\title{
Anaerobic endosymbiont generates energy for ciliate host by denitrification
}

https://doi.org/10.1038/s41586-021-03297-6

Received: 10 December 2019

Accepted: 27 January 2021

Published online: 3 March 2021

\section{Open access}

Check for updates

\author{
Jon S. Graf ${ }^{1 \bowtie}$, Sina Schorn', Katharina Kitzinger ${ }^{1,2}$, Soeren Ahmerkamp ${ }^{1}$, Christian Woehle ${ }^{3}$ \\ Bruno Huettel $^{3}$, Carsten J. Schubert ${ }^{4}$, Marcel M. M. Kuypers ${ }^{1}$ \& Jana Milucka ${ }^{1 凶}$
}

Mitochondria are specialized eukaryotic organelles that have a dedicated function in oxygen respiration and energy production. They evolved about 2 billion years ago from a free-living bacterial ancestor (probably an alphaproteobacterium), in a process known as endosymbiosis ${ }^{1,2}$. Many unicellular eukaryotes have since adapted to life in anoxic habitats and their mitochondria have undergone further reductive evolution ${ }^{3}$. As a result, obligate anaerobic eukaryotes with mitochondrial remnants derive their energy mostly from fermentation ${ }^{4}$. Here we describe 'Candidatus Azoamicus ciliaticola', which is an obligate endosymbiont of an anaerobic ciliate and has a dedicated role in respiration and providing energy for its eukaryotic host. 'Candidatus A. ciliaticola' contains a highly reduced 0.29-Mb genome that encodes core genes for central information processing, the electron transport chain, a truncated tricarboxylic acid cycle, ATP generation and iron-sulfur cluster biosynthesis. The genome encodes a respiratory denitrification pathway instead of aerobic terminal oxidases, which enables its host to breathe nitrate instead of oxygen. 'Candidatus A. ciliaticola' and its ciliate host represent an example of a symbiosis that is based on the transfer of energy in the form of ATP, rather than nutrition. This discovery raises the possibility that eukaryotes with mitochondrial remnants may secondarily acquire energy-providing endosymbionts to complement or replace functions of their mitochondria.
Eukaryotic life evolved at least around 1-1.9 billion years ago ${ }^{5,6}$, after the gradual oxygenation of the atmosphere of the Earth (which started about 2.4 billion years ago $0^{7,8}$ ). The ensuing diversification of eukaryotes has been attributed to their ability to harvest copious amounts of energy from the respiration of oxygen, an abundant, high-potential electron acceptor. Oxygen respiration is performed in mitochondria, which are specialized subcellular organelles that arose from a free-living prokaryotic organism through endosymbiosis ${ }^{9}$. During the evolution towards the contemporary organelle, the endosymbiont has either lost its genes or transferred them to the host genome; mitochondria have kept only a small subset of genes ${ }^{10}$ that pertain to translation and the electron transport chain ${ }^{11,12}$.

Some eukaryotes that inhabit anoxic environments do not contain aerobic mitochondria. Originally thought to be 'ancestral ${ }^{13}$, all of these amitochondriate eukaryotes in fact evolved secondarily from predecessors that had aerobic mitochondria ${ }^{14}$; they possess highly reduced mitochondria-related organelles or at least contain genes of mitochondrial origin in their nuclear genomes ${ }^{15}$. Throughout the course of evolution, anaerobic unicellular protists have lost the capacity to generate ATP via oxidative phosphorylation (with some exceptions ${ }^{16,17}$ ). Instead, these eukaryotes generate ATP from fermentation through substrate-level phosphorylation, coupled to the formation of $\mathrm{H}_{2}$ (ref. ${ }^{18}$ ). This reaction takes place in the cytoplasm or-more commonly-in hydrogenosomes. Hydrogenosomes are specialized organelles, which have independently evolved from mitochondria in evolutionarily distant organisms $\mathrm{s}^{18,19}$. Some ciliates that contain hydrogenosomes also contain endosymbiotic methanogenic archaea that scavenge the produced $\mathrm{H}_{2}$, which thereby increases the energy yield of the reaction ${ }^{20}$.

In contrast to strict anaerobes that exclusively ferment, some facultatively anaerobic eukaryotes can perform anaerobic respiration ${ }^{21}$. Nitrate and/or nitrite reduction has previously been demonstrated for some foraminifera and Gromiida ${ }^{22-24}$, fungi ${ }^{25,26}$ and the ciliate Loxodes ${ }^{27}$. The underlying molecular mechanism of eukaryotic denitrification and energy conservation is largely unknown. Here we report the discovery of an obligate endosymbiont of an anaerobic ciliate that provides its host with energy derived from denitrification.

\section{Anaerobic ciliates with bacterial endosymbionts}

We investigated Lake Zug, an approximately 200-m deep and permanently stratified freshwater lake that is located in Switzerland. Lake Zug contains deep waters that remain permanently anoxic and replete in nitrate, which is a feature that is characteristic of many stratified fresh and marine waters depleted in oxygen. The thickness of the anoxic hypolimnion varied between 40 and 100 m over a period of 5 years (2016-2020) (Extended Data Fig.1). In 2018, oxygen was undetectablebelow a depth of $160 \mathrm{~m}$, and a decrease in $\mathrm{NO}_{x}$ (mainly nitrate) concentration below the base of the oxycline indicated ongoing denitrification (Extended Data Fig.1).

${ }^{1}$ Max Planck Institute for Marine Microbiology, Bremen, Germany. ${ }^{2}$ Division of Microbial Ecology, Centre for Microbiology and Environmental Systems Science, University of Vienna, Vienna, Austria. ${ }^{3}$ Max Planck Genome Centre Cologne, Max Planck Institute for Plant Breeding Research, Cologne, Germany. ${ }^{4}$ Surface Waters - Research and Management, Eawag, Kastanienbaum, Switzerland. ${ }^{凶}$ e-mail: jgraf@mpi-bremen.de; jmilucka@mpi-bremen.de 
a

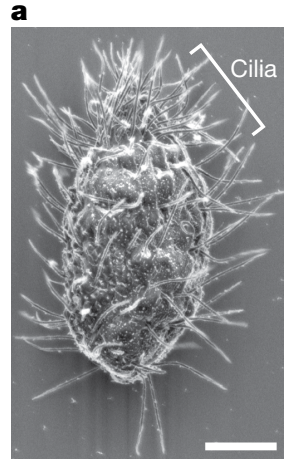

e

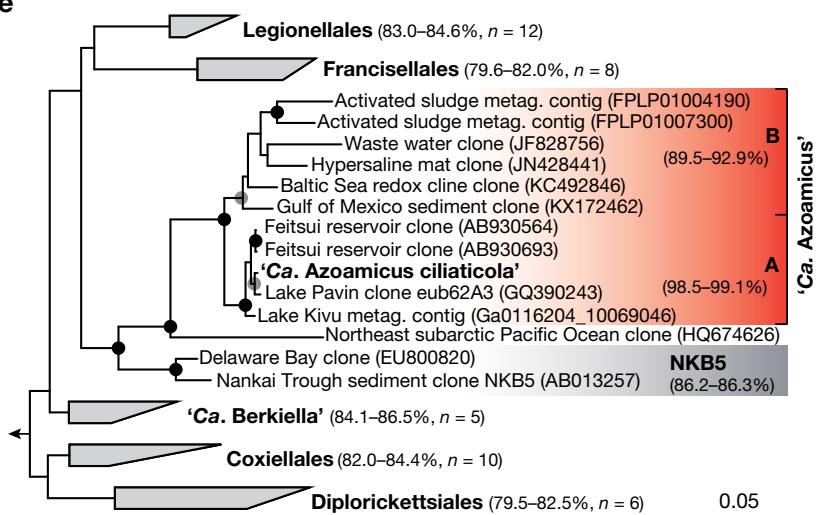

b

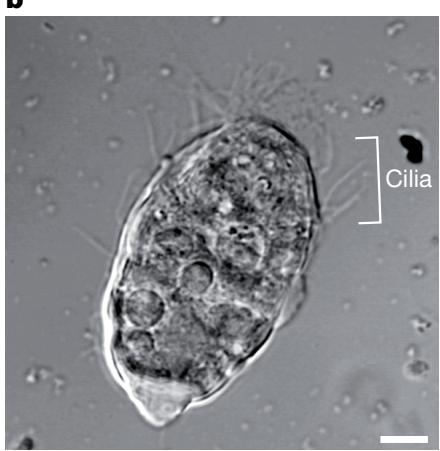

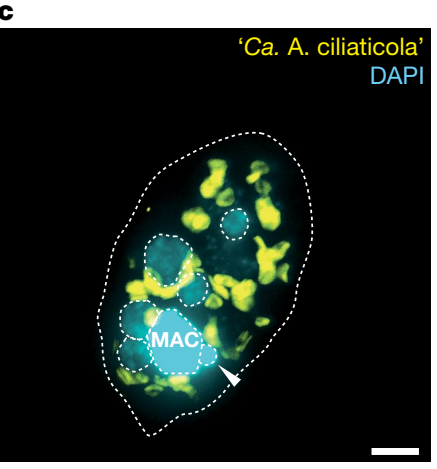

f

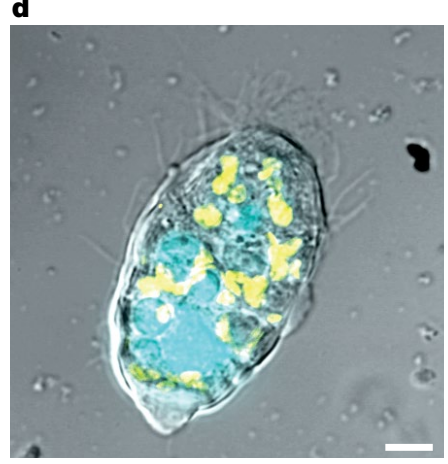

\section{¿ู $\dot{8}$}

Plagiopylida

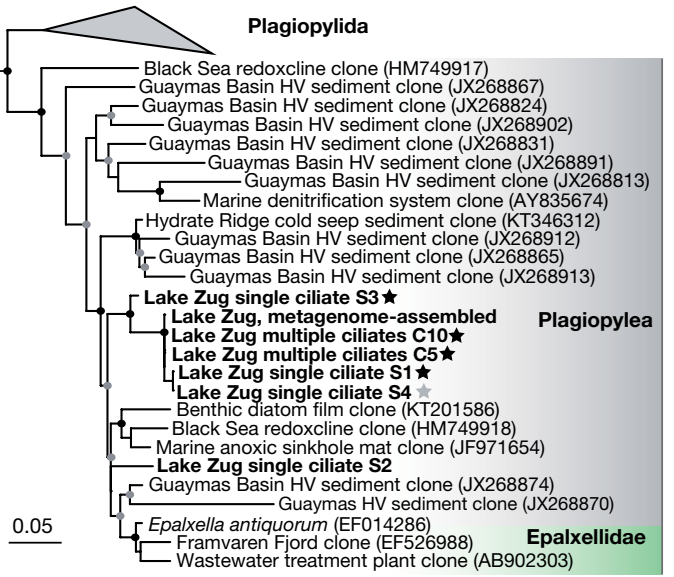

Fig. 1 Visualization and phylogenetic affiliation of ' $\mathrm{Ca}$. A. ciliaticola' and its ciliate host. a, Representative scanning electron microscopy image of a ciliate from the anoxic hypolimnion of Lake Zug (February 2020, depth of $186 \mathrm{~m})$. Scale bar, $5 \mu \mathrm{m}$. b-d, Differential interference contrast image (b) and confocal laser scanning microscopy image (c) of a ciliate after hybridization with a 'Ca. Azoamicus'-specific oligonucleotide probe (eub62A3_813) (yellow) and counterstaining with DAPI (blue). d, Overlay of fluorescence and differential interference contrast images. The macronucleus (MAC) with attached micronucleus (arrowhead) and putative food vacuoles of the ciliate are outlined. Scale bars, $5 \mu \mathrm{m}$.e, $16 \mathrm{~S}$ rRNA gene sequence-based maximum likelihood phylogenetic tree of ' $C a$. A. ciliaticola' (bold denotes sequence derived from circular metagenome-assembled genome) and members of related gammaproteobacterial orders and environmental clades. Subgroups $A$ and B of the ' $\mathrm{Ca}$. Azoamicus' group are indicated. The sequence similarities of respective groups to the $16 \mathrm{~S}$ rRNA gene sequence of ' $\mathrm{Ca}$. A. ciliaticola' are shown in parentheses. The full tree is shown in Extended Data Fig. 4. Taxonomic groups were assigned on the basis of SILVA taxonom $y^{45}$. Metag., metagenome.f, Ciliate 18S rRNA gene sequence-based maximum likelihood phylogenetic tree of the class Plagiopylea based on EukRef-Ciliophora reference alignment ${ }^{30}$. Sequences of ciliates from Lake Zug (in bold) were amplified from individual ciliates (S1-S4) or combined ciliates ( $\mathrm{C} 5$ and $\mathrm{C10}$ ). Stars denote positive identification of a ' $\mathrm{Ca}$. A. ciliaticola' $16 \mathrm{~S}$ rRNA sequence amplified from the same ciliate: black, ' $C a$. A. ciliaticola' $16 \mathrm{~S}$ rRNA gene sequence verified by Sanger sequencing; grey, positive band on gel. For both trees, bootstrap values are shown as circles at the respective nodes, and indicate bootstrap support of $>70 \%$ (grey) or $>90 \%$ (black) out of 100 resamplings. Scale bars, 0.05 nucleotide substitutions per site.
We observed a high abundance of motile unicellular eukaryotes throughout the anoxic layer (Fig. 1, Extended Data Fig.1, Supplementary Video 1). Many of these eukaryotes contained macro- and micronuclei and had the typical morphology of ciliates (Fig. 1, Extended Data Fig. 2). Their abundances increased from about 6,000 cells per litre at the base of the oxycline (a depth of $160 \mathrm{~m}$ ) to around 25,000 cells per litre within the core of the anoxic hypolimnion (a depth of about $180 \mathrm{~m}$ ) (Supplementary Table 1). The ciliates exhibited negative aerotaxis, which indicates an obligate anaerobic lifestyle (Extended Data Fig. 3). In some cases, we observed fragmented and densely packed 4',6-diamidino-2-phenylindole (DAPI) signals that might have depicted microbial prey in food vacuoles (Fig. 1, Extended Data Fig. 2). However, a substantial fraction of the ciliates observed in the anoxic hypolimnion also contained multiple intracellular DAPI signals that were reminiscent of endosymbionts. These putative endosymbionts did not show the typical cofactor $\mathrm{F}_{420}$ autofluorescence that is indicative of methanogen-hydrogenosome assemblages (which are often found in anaerobic ciliates) nor did they hybridize with a general archaeal oligonucleotide probe (Extended Data Fig. 2). We further confirmed the absence of methanogenic archaea in the ciliate by single-ciliate transcriptome sequencing (Supplementary Table 13, Supplementary Discussion). Instead, we obtained clear fluorescent signals after hybridization with a general bacteria-specific oligonucleotide probe (EUB-I) (Supplementary Table 3), which identified the potential ciliate endosymbionts as bacteria (Extended Data Fig. 2).

\section{Endosymbiont and host phylogeny}

To identify the putative endosymbiont, we used DNA extracted from the anoxic lake water for metagenome sequencing (Supplementary Table 4). We identified a small (about $290 \mathrm{~kb}$ ), circular metagenome-assembled genome with typical endosymbiotic features (as described in 'Bacterial genome with endosymbiotic features'). The 16S rRNA gene sequence retrieved from the endosymbiont circular metagenome-assembled genome shared the highest identities (about 86\%) with Legionella clemsonensis and 'Candidatus Berkiella cookevillensis' C99, which is an intranuclear bacterium of Acanthamoeba polyphaga. Given the high degree of sequence divergence between the endosymbiont and related bacteria, we named this organism 'Candidatus Azoamicus ciliaticola' (see Methods for etymology).

Our phylogenetic analysis showed that ' $\mathrm{Ca}$. A. ciliaticola' belongs to the understudied eub62A3 group of the Gammaproteobacteria (Fig.1e, Extended Data Fig. 4). The eub62A3 group (which we refer to as the 'Candidatus Azoamicus' group) probably represents its own order 

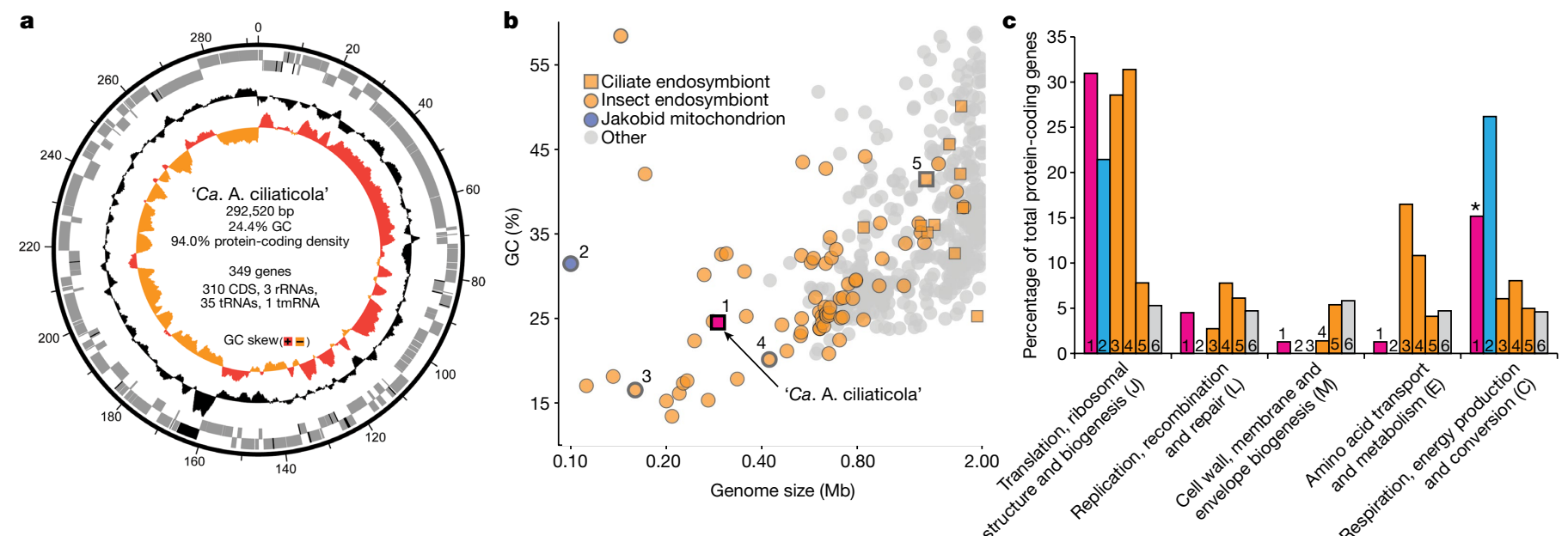

Fig. 2 | Features of the genome of ' $\mathbf{C a}$. A. ciliaticola'. a, Circular genome plot of 'Ca. A. ciliaticola', showing (from inside to outside) GC skew (red, positive; light orange, negative), GC content, RNA (black) and protein-coding genes (grey) encoded on forward or reverse strand of the genome (in kb). b. Relationship between genome size and GC content of complete prokaryotic genomes deposited at GenBank (cut-off at $2 \mathrm{Mb}$; accessed May 2018). Genomes of ' $\mathrm{Ca}$. A. ciliaticola',Jakoba libera mitochondrion, and endosymbionts of insects and ciliates are highlighted.1, 'Ca. A. ciliaticola'; 2,J. libera mitochondrion; 3, 'Ca. Carsonella ruddii' PV; 4, Buchnera aphidicola; 5, Caedibacter taeniospiralis.
Legionella clemsonensis is not shown in this panel as its genome size (3.27 Mb) exceeds the depicted range.c, Comparison of the number of genes in selected functional gene categories (as a percentage of total protein-coding genes) (Supplementary Table 9) between 'Ca. A. ciliaticola' (magenta), J. libera mitochondrion (blue), selected insect and ciliate endosymbionts (orange), and Legionella clemsonensis (grey) as an example of a related free-living bacterium. Numbers are as described in $\mathbf{b} ; 6$ denotes L.clemsonensis. The asterisk highlights the presence of an anaerobic respiratory chain. Single-letter codes of COG functional categories are shown in parentheses. within Gammaproteobacteria. The 'Ca. Azoamicus' group appears to consist of at least two distinct subgroups. Sequences affiliated with subgroup A are closely related to ' $\mathrm{Ca}$. A. ciliaticola' (98.5-99.1\% sequence identity) and have been retrieved from geographically distant anoxic freshwater lakes and reservoirs (Fig. 1e). Subgroup B contains sequences that are more divergent from ' $C a$. A. ciliaticola' $(89.5-92.9 \%$ sequence identity) and that have been retrieved from more diverse aquatic habitats (Fig. 1e).

We used a fluorescently labelled ' $\mathrm{C}$ a. Azoamicus'-specific oligonucleotide probe (eub62A3_813) (Extended Data Fig. 5, Methods, Supplementary Table 3 ), and found that the endosymbionts were exclusively located inside small ovoid $(25.4 \pm 3.2-\mu \mathrm{m}$ long, $19.5 \pm 2.0-\mu \mathrm{m}$ wide ( \pm s.d. from average); $n=9$ cells) ciliate hosts (Fig. 1, Extended Data Fig. 2). In 2018, all the ciliates we found at $180 \mathrm{~m}$ depth contained the 'Ca. A. ciliaticola' symbiont (Supplementary Table 1). We extracted DNA from individually picked ciliates from the deepest depth $(189 \mathrm{~m}$, which was sampled in 2019) and amplified ' C $a$. A. ciliaticola' 16S rRNA gene using specific primers (Supplementary Table 2). We successfully retrieved sequences that were closely related to ' $\mathrm{C}$ a. A. ciliaticola' (96.5-99.9\% identity) from the picked ciliates. Our analysis of the partial 18S rRNA gene amplified from the same DNA extracts using ciliate-specific primers ${ }^{28}$ (Supplementary Fig. 1) identified all of the picked ciliates as members of the class Plagiopylea within the Ciliophora phylum (Fig. 1f). We further confirmed their Ciliophora affiliation by analyses of single-copy orthologous gene transcripts from single-ciliate transcriptomes (Extended Data Fig. 6). Plagiopyleans are anaerobic or micro-aerobic ciliates that are typically found in anoxic freshwater or marine habitats. They are generally thought to rely on hydrogenosomes, and some host methanogenic archaea ${ }^{29}$. The class Plagiopylea is phylogenetically divided into two clades ${ }^{30}$. One clade contains well-described members of the order Plagiopylida (such as Plagiopyla frontata and Trimyema compressum), and the second clade contains our ' $\mathrm{C}$ a. A. ciliaticola'-associated plagiopylean ciliate as well as diverse 18S rRNA gene sequences from freshwater and marine anoxic habitats (Fig. 1f). Our phylogenetic analyses thus indicated that ' $\mathrm{Ca}$. A. ciliaticola' represents an endosymbiont of an anaerobic freshwater plagiopylean ciliate.

\section{Bacterial genome with endosymbiotic features}

The closed genome of ' $\mathrm{Ca}$. A. ciliaticola' is very small (292,520 bp), and has a notably low average $\mathrm{G}+\mathrm{C}$ content $(24.4 \%)$ and a high protein-coding density (94.0\%) (Fig. 2a). It has retained 310 protein-coding genes, 1 ribosomal RNA operon (16S, 23S and 5S), 35 transfer RNAs that decode all 20 standard amino acids (genetic code 11) and 1 transfer-messenger RNA; as such, it is, to our knowledge, the smallest protist endosymbiont genome reported to date. Genomes of a similar size and with similar general features have thus far been found only in obligate endosymbionts of insects ${ }^{31,32}$ (Fig. 2b). On the basis of these similarities, we concluded that ' $\mathrm{Ca}$. A. ciliaticola' is an obligate endosymbiont.

'Candidatus A. ciliaticola' encodes a similar proportion of genes related to translation, replication and repair to that encoded by other highly reduced endosymbionts of ciliates and insects (Fig. 2c). The genome encodes several subunits of the DNA polymerase III holoenzyme (dnaE, dnaQ and dnaX), DNA-directed RNA polymerase ( $r p o A$, $r p o B, r p o C, r p o D, r p o H$ and $r p o Z$ ) and a complete gene set of $30 \mathrm{~S}$ and $50 \mathrm{~S}$ ribosomal proteins. These genes were highly transcribed and accounted for around $20 \%$ of cumulative transcripts per million (Extended Data Fig. 7). Therefore, ' $C a$. A. ciliaticola'-despite its reduced genomeappears to be capable of self-replication inside its host.

By contrast, the ' $\mathrm{Ca}$. A. ciliaticola' genome exhibits extensive loss of the genes that underlie cell wall, membrane and envelope biogenesis. The genetic repertoire for the biosynthesis of vitamins and amino acids is also markedly reduced, which is notably different from other endosymbionts of insects or ciliates (Fig. 2c, Extended Data Fig. 7). As many endosymbionts provide essential amino acids or vitamins to supplement the nutritionally poor diets of their hosts, they often retain extensive biosynthetic pathways for these compounds ${ }^{32}$. The ' $\mathrm{Ca}$. A. ciliaticola' genome encodes only three copies of a tyrosine and tryptophan transporter (tyr $P$ ) and a glutamate and $\gamma$-aminobutyrate (glutamate $/ \gamma$-aminobutyrate) antiporter that might serve to import aromatic amino acids and glutamate into the cell. Notably, ' $\mathrm{Ca}$. A. ciliaticola' appears to depend on its host for most of the other essential cellular building blocks (for example, nucleotides, phospholipids and lipopolysaccharides), as no genes for their biosynthesis are encoded in the genome. It is therefore puzzling 

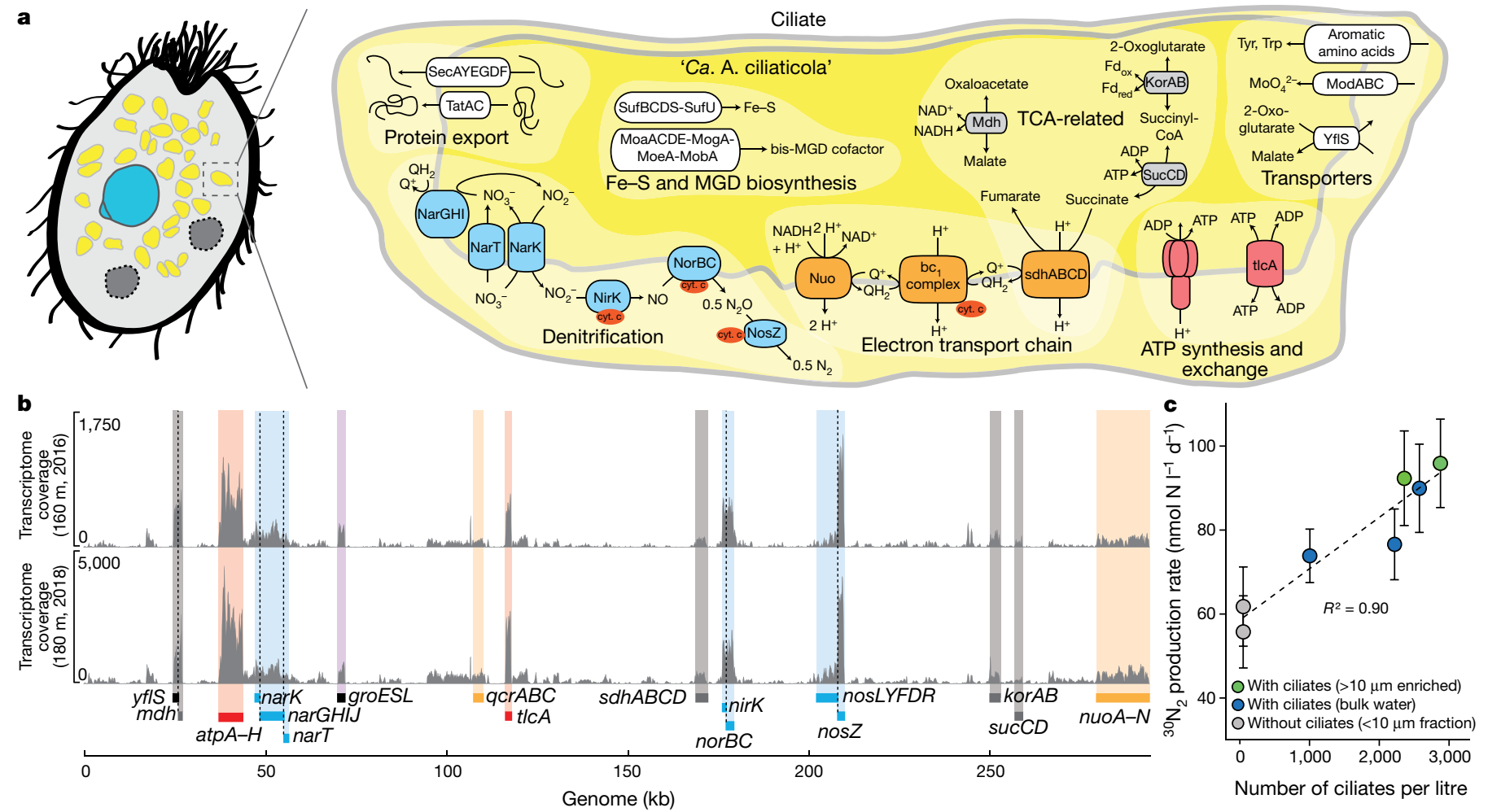

Fig. 3 | Metabolic potential and activity of ' $C \boldsymbol{C}$. A. ciliaticola'.

a, Genome-inferred metabolic potential related to anaerobic respiration via denitrification, ATP generation and exchange, tricarboxylic acid (TCA) cycle, iron-sulfur-cluster (Fe-S) and bis-molybdopterin guanine dinucleotide (bis-MGD) biosynthesis, protein export and other transporters. The presence of a double membrane is presumed by analogy with mitochondria.

b, Metatranscriptome coverage of two metatranscriptomic datasets, from samples obtained in 2016 and 2018 , of the ' $C a$. A. ciliaticola' genome. There is a highly consistent transcriptome profile between years and an exceptionally high transcription of genes related to energy conservation, ATP production and transport, chaperones (groE, groS and groL) and denitrification (orange, red, purple and blue shading, respectively). Coverage was corrected for

that, similar to other obligate endosymbionts ${ }^{33}$, the ' $\mathrm{Ca}$. A. ciliaticola' genome largely lacks transport systems for these metabolites (Supplementary Tables 5, 6, Supplementary Discussion). Other genes that have previously been shown to be related to nutritional (for example, those that encode pectinase ${ }^{34}$ ) or defensive symbioses known from ciliates ${ }^{35}$ are also absent from the genome.

\section{Anaerobic respiration and energy metabolism}

In contrast to most other functional gene categories, genes related to respiration and energy production and conversion (Figs. 2c, 3a, Supplementary Table 5) are abundantly retained in the ' $\mathrm{Ca}$. A. ciliaticola' genome. 'Candidatus A. ciliaticola' encodes a complete ATP-generating electron transport chain, including NADH dehydrogenase (nuoA to nuoN), cytochrome $b c_{1}$ complex $(q c r A, q c r B$ and $q c r C)$ and ATP synthase (atpA to $a t p H)$. In many endosymbionts, genes related to respiration and energy production and conversion are affected by marked losses; some endosymbionts are even thought to be ATP parasites ${ }^{32}$. Instead, a substantial fraction of the ' $\mathrm{Ca}$. A. ciliaticola' genome is dedicated to energy production and conversion, which is a feature that it shares with all known mitochondrial genomes (Fig. 2c).

The ' $\mathrm{C}$. A. ciliaticola' genome does not encode genes for aerobic respiration, such as terminal oxidases (for example, cytochrome $c$ oxidase and cytochrome $b d$ oxidase). In principle, the terminal oxidase genes could have been relocated to the nuclear genome (as is the sequencing depth; the higher coverage in the 2018 sample is due to the higher endosymbiont abundance in that year. Genes related to denitrification (blue), electron transport chain (orange), tricarboxylic acid cycle (grey) and ATP generation as well as transport (red) are highlighted. The highlighted genes account for more than $55 \%$ of all transcripts. Further information is provided in Supplementary Table 5).c, Correlation of ciliate abundance and denitrification rates $\left({ }^{30} \mathrm{~N}_{2}\right.$ production) in water from the anoxic hypolimnion (189 $\mathrm{m}$, May 2019) with and without ciliates. Each data point represents a volumetric denitrification rate calculated from the linear regression of six individual time points of an experiment. Error bars represent s.e. from linear regression. Denitrification rates in incubations without ciliates are due to the activity of denitrifying bacteria that are still present in the water.

case with many endosymbiont genes). However, electron transport chain complexes I, II, IV and V are conserved in the mitochondrial core genome across many eukaryotes, and it is expected that genes that encode components of the electron transport chain are amongst the least likely to be transferred to the nucleus ${ }^{11}$. We also did not find transcripts for mitochondrially encoded cytochrome $c$ oxidase in the host transcriptome (Supplementary Table 10, Supplementary Discussion). This confirms the obligate anaerobic nature of the host, as was already indicated by its negative aerotactic behaviour (Extended Data Fig. 3).

The ' $\mathrm{Ca}$. A. ciliaticola' genome encodes a complete gene set for respiratory denitrification (Fig. 3a, Supplementary Table 5). The gene set contains all four core enzymes: nitrate reductase ( arG, narH and narl), copper-containing nitrite reductase (nirK), nitric oxide reductase (norB and $\operatorname{nor} C$ ) and nitrous oxide reductase (nosZ). These genes are complemented by a wide variety of accessory proteins, such as cytochromes $c_{4}$ and $c_{5}$ for redox coupling, enzyme maturation factors (narJ, nos $R$, nos $D, \operatorname{nos} F, \operatorname{nos} Y$ and $n o s L$ ), and nitrate and nitrite transporters (narK and narT). 'Candidatus A. ciliaticola' encodes a molybdate import system $(\bmod A, \bmod B$ and $\bmod C)$ and a pathway for the biosynthesis of bis-molybdopterin guanine dinucleotide, which is an essential cofactor of nitrate reductase. In eukaryotes, this pathway is-for the most part-a cytosolic process that is encoded by nuclear genes ${ }^{36}$. Similarly, a pathway of iron-sulfur-cluster biosynthesis (Suf-type) (sufB, sufC, sufD and sufS) is also encoded in the ' $\mathrm{Ca}$. A. ciliaticola' genome; this was the only pathway that we detected for iron-sulfur-cluster biosynthesis 


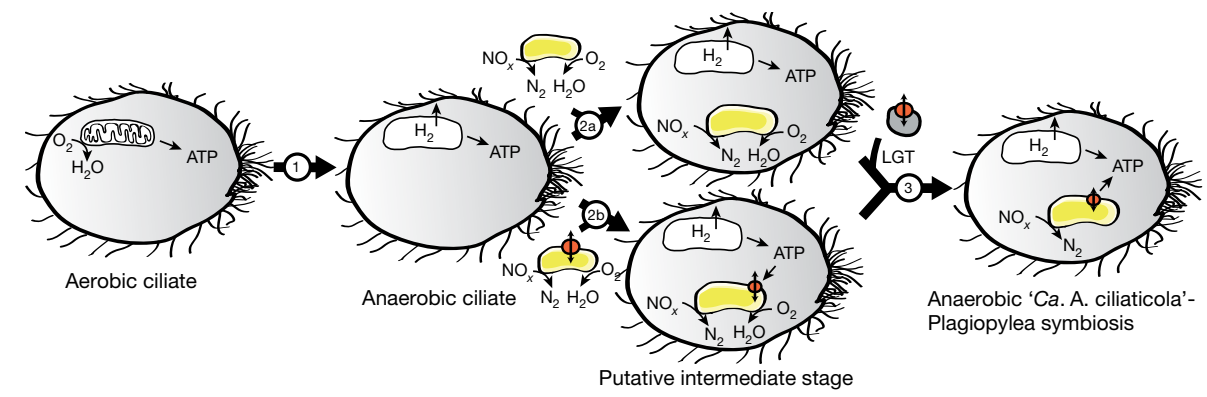

Fig. 4 | Hypothesized evolution of ' $\mathrm{Ca}$. A. ciliaticola'-ciliate symbiosis. (1) Secondary adaptation of an aerobic ciliate to an anoxic, nitrate-containing environment involved the deterioration of its aerobic mitochondria and the formation of hydrogenosomes. (2) Acquisition of a facultatively anaerobic, denitrifying bacterium that entered the anaerobic ciliate host either via endocytosis (2a) or as a parasite (2b). In the latter case, the ' $\mathrm{Ca}$. A. ciliaticola' ancestor might have already possessed an ATP/ADP translocase for energy parasitism. (3) Alternatively, the ATP/ADP translocase was acquired at a later point via lateral gene transfer (LGT) from (for example) an alphaproteobacterial cosymbiont in the host cell. Persistent anoxic and nitrate-rich conditions would result in the loss of genes for oxygen respiration that gave rise to the present-day ' $C a$. A. ciliaticola'-Plagiopylea symbiosis. The presence of hydrogenosomes in the extant host is based on indications from single-ciliate transcriptome sequencing, and is yet to be conclusively confirmed. in the ciliate host. We did not detect transcripts that pertain to the Isc-type pathway of iron-sulfur-cluster biosynthesis (which operates in hydrogenosomes, mitochondria and mitochondria-related organelles) in the single-ciliate transcriptome (Supplementary Table 11).

Although the trait of respiratory denitrification is widespread among free-living prokaryotes ${ }^{37,38}$, to our knowledge no obligate endosymbiont described to date encodes a denitrification pathway. We confirmed active denitrification by ciliates using ${ }^{15} \mathrm{~N}$ stable isotope incubations (Fig. 3c, Extended Data Fig. 8, Supplementary Discussion). Possible electron donors for denitrification might be di-and/or tri-carboxylates provided by the tricarboxylic acid cycle, such as succinate and malate (Supplementary Discussion). Malate is used by many known energy-producing anaerobic mitochondria or hydrogenosomes of ciliates or other protists ${ }^{4}$. The high transcription of malate dehydrogenase ( $m d h$ ) and a putative 2-oxoglutarate and malate (2-oxoglutarate/malate) transporter ( $y f l S)$ (Fig. 3b) indicates that malate also has a key role in the metabolism of ' $\mathrm{C}$. A. ciliaticola'. Similarly, genes related to energy conservation-including ATP synthase ( $a t p A$ to $a t p H)$ and denitrification genes (narG, narH, narl, nirK, norB, norC and nosZ)-were among those showing the highest transcription (Fig. 3b) and, altogether, we found that more than half of the transcriptional effort of ' $\mathrm{Ca}$. A. ciliaticola' was devoted to energy production and conversion (Extended Data Fig. 7).

Crucially, the ' $C a$. A. ciliaticola' genome also contains a putative ATP and ADP (hereafter, ATP/ADP) translocase gene $(t l c A)$ that encodes a single-domain nucleotide transport protein. These nucleotide transport proteins have canonical roles in energy transfer in plastids and intracellular parasites, although these might not be their only functions ${ }^{39}$. The 'Ca. A. ciliaticola' nucleotide transport protein has several conserved residues that are critical for function and substrate specificity of ATP/ ADP translocases (Extended Data Fig. 9, Supplementary Discussion). Moreover, the $t l c A$ gene was among the ten highest transcribed ' $\mathrm{Ca}$. A. ciliaticola' genes, together with other genes that are involved in energy conservation (Fig. 3b). On this basis, we speculate that the TlcA nucleotide transporter serves to exchange ATP and ADP between ' $\mathrm{Ca}$. A. ciliaticola' and its host. As ' $\mathrm{C}$ a. A. ciliaticola' lacks the ability to synthesize any nucleotides de novo, this nucleotide transport protein might also be involved in the uptake of nucleotides other than ATP and ADP.

As is known from other obligate endosymbionts, the genome of ' $\mathrm{Ca}$. A. ciliaticola' has presumably preserved traits that are beneficial to the host. Given the fact that the highly reduced genome of ' $\mathrm{Ca}$. A. ciliaticola' has retained an extensive genetic potential for energy metabolism, the main function of this endosymbiont thus appears to be the production of ATP for its host. In this respect, the function of ' $\mathrm{Ca}$. A. ciliaticola' is strongly evocative of mitochondria and hydrogenosomes (that is, eukaryotic energy-providing organelles). On the basis of our combined metagenomic and transcriptomic results, we propose that ' $\mathrm{Ca}$. A. ciliaticola' functions as a respiratory endosymbiont that conserves and provides energy from anaerobic respiration for its plagiopylean host.

\section{Evolution of the respiratory symbiosis}

Unicellular eukaryotes that have secondarily adapted to an anaerobic lifestyle often possess mitochondria-related organelles such as hydrogenosomes. These organelles have retained their energy-generating function-although they have often lost their genomes, and their enzymes are predominantly nuclear-encoded and expressed by the eukaryotic host ${ }^{40}$. When analysing the single-cell transcriptomes of the ciliate host, we found transcripts that potentially encode hydrogenosomal proteins (Supplementary Tables 11,12, Supplementary Methods, Supplementary Discussion). This suggests that our ciliate host-as with all eukaryotes known to date-may contain remnants of a mitochondrial organelle, which is probably capable of hydrogenosomal metabolism (Fig. 4).

The putative presence of hydrogenosomes in the extant host implies that, at some point, its ancestor possessed aerobic mitochondria. However, in a host that is capable of aerobic respiration, the acquisition of a denitrifying endosymbiont is unlikely to have increased the fitness of the host sufficiently to warrant stable integration. It is thus more likely that the ciliate host was already a hydrogenosome-containing obligate anaerobe before the acquisition of the predecessor of ' $\mathrm{Ca}$. A. ciliaticola' (Fig. 4). A fermenting eukaryote that possessed only rudimentary means of energy generation would have profited considerably from the acquisition of a bacterium with the capacity for anaerobic nitrate respiration and chemiosmotic ATP production. The positive effect of the ' $\mathrm{C}$ a. A. ciliaticola' endosymbiont on the fitness of the ciliate host could explain our observation that only ' $\mathrm{Ca}$. A. ciliaticola'-containing ciliates were observed in the deep anoxic nitrate-containing waters of Lake Zug (Supplementary Table 1).

The predecessor of ' $\mathrm{Ca}$. A. ciliaticola' may have entered its host as a parasite, as many members of the related Legionellales and Francisellales groups are parasitic. Alternatively, the bacterial predecessor could have been acquired through endocytosis and then persisted intracellularly after managing to escape digestion, as has previously been suggested for some bacteria ${ }^{41}$. In either case, the protein that was probably fundamental for the integration of the bacterium into its host is the ATP/ADP transporter. Phylogenetic analyses showed that the putative ATP/ADP translocase of ' $C a$. A. ciliaticola' clusters with mostly alphaproteobacterial nucleotide transporter sequences from uncharacterized metagenomic sequences related to Holosporales or Caedibacter (Extended Data Fig.10), which are known to be intracellular parasites or endosymbionts 
of ciliates $^{42,43}$. Considering that the free-living predecessor of ' $\mathrm{Ca}$. A. ciliaticola' was a gammaproteobacterium, we speculate that the ATP/ADP translocase might have been obtained via lateral gene transfer from an alphaproteobacterial donor (for example,Holospora-related) (Supplementary Discussion). At this point, it is not clear whether the lateral gene transfer happened before or after the engulfment of the predecessor of 'Ca. A. ciliaticola' by the ciliate (Fig. 4).

In its extant form, 'Ca. A. ciliaticola' encodes only the denitrification respiratory chain. This is noteworthy as almost all pro- and eukaryotic denitrifying organisms known to date possess a hybrid respiratory chain that is also capable of oxygen respiration ${ }^{38,44}$. On this basis, it seems likely that the predecessor of ' $\mathrm{Ca}$. A. ciliaticola' acquired by the ciliate host was a facultatively anaerobic denitrifying bacterium (Fig. 4). Subsequently, it might have lost its capacity for oxygen respiration when it became superfluous in a ciliate that exclusively inhabited anoxic waters. However, any gene loss in ' $\mathrm{Ca}$. A. ciliaticola' might also be the result of genetic drift, which is known to affect obligate endosymbionts with small population sizes and restricted gene flow ${ }^{31}$.

Over the course of its existence, ' $\mathrm{C}$ a. A. ciliaticola' has evolved into an obligate endosymbiont with a distinct role in respiration and energy generation for its host; in eukaryotes, these roles are traditionally reserved for mitochondria and related organelles. Even though the ciliate host might contain mitochondria-related organelles (that is, putative hydrogenosomes), it appears that quintessential mitochondrial functions related to respiration, the electron transport chain, oxidative phosphorylation and iron-sulfur-cluster biosynthesis are taking place in its endosymbiont.

'Candidatus A. ciliaticola' therefore represents an example of an obligate endosymbiont that has retained cellular functions that are markedly similar to those of mitochondria, although it did not originate from the mitochondrial line of descent. This discovery provokes the question of whether other prokaryotic endosymbionts may enable eukaryotes to tap into the broad pool of electron acceptors that is available in nature.

\section{Online content}

Any methods, additional references, Nature Research reporting summaries, source data, extended data, supplementary information, acknowledgements, peer review information; details of author contributions and competing interests; and statements of data and code availability are available at https://doi.org/10.1038/s41586-021-03297-6.

1. Martijn, J., Vosseberg, J., Guy, L., Offre, P. \& Ettema, T. J. G. Deep mitochondrial origin outside the sampled alphaproteobacteria. Nature 557, 101-105 (2018).

2. Fan, L. et al. Phylogenetic analyses with systematic taxon sampling show that mitochondria branch within Alphaproteobacteria. Nat. Ecol. Evol. 4, 1213-1219 (2020).

3. Hjort, K., Goldberg, A. V., Tsaousis, A. D., Hirt, R. P. \& Embley, T. M. Diversity and reductive evolution of mitochondria among microbial eukaryotes. Phil. Trans. R. Soc. Lond. B 365 , 713-727 (2010)

4. Müller, M. et al. Biochemistry and evolution of anaerobic energy metabolism in eukaryotes. Microbiol. Mol. Biol. Rev. 76, 444-495 (2012).

5. Parfrey, L. W., Lahr, D. J. G., Knoll, A. H. \& Katz, L. A. Estimating the timing of early eukaryotic diversification with multigene molecular clocks. Proc. Natl Acad. Sci. USA 108, 13624-13629 (2011).

6. Eme, L., Sharpe, S. C., Brown, M. W. \& Roger, A. J. On the age of eukaryotes: evaluating evidence from fossils and molecular clocks. Cold Spring Harb. Perspect. Biol. 6, a016139 (2014).

7. Bekker, A. et al. Dating the rise of atmospheric oxygen. Nature 427, 117-120 (2004).

8. Lyons, T. W., Reinhard, C. T. \& Planavsky, N. J. The rise of oxygen in Earth's early ocean and atmosphere. Nature 506, 307-315 (2014).

9. Sagan, L. On the origin of mitosing cells. J. Theor. Biol. 14, 225-274 (1967).

10. Gray, M. W. Mosaic nature of the mitochondrial proteome: implications for the origin and evolution of mitochondria. Proc. Natl Acad. Sci. USA 112, 10133-10138 (2015).

11. Roger, A. J., Muñoz-Gómez, S. A. \& Kamikawa, R. The origin and diversification of mitochondria. Curr. Biol. 27, R1177-R1192 (2017).

12. Wideman, J. G. et al. Unexpected mitochondrial genome diversity revealed by targeted single-cell genomics of heterotrophic flagellated protists. Nat. Microbiol. 5, 154-165 (2020).

13. Cavalier-Smith, T. Eukaryotes with no mitochondria. Nature 326, 332-333 (1987).
14. Gray, M. W., Burger, G. \& Lang, B. F. Mitochondrial evolution. Science 283, 1476-1481 (1999).

15. Karnkowska, A. et al. A eukaryote without a mitochondrial organelle. Curr. Biol. 26, 1274-1284 (2016).

16. Gawryluk, R. M. R. et al. The earliest stages of mitochondrial adaptation to low oxygen revealed in a novel rhizarian. Curr. Biol. 26, 2729-2738 (2016).

17. Lewis, W. H. et al. Convergent Evolution of hydrogenosomes from mitochondria by gene transfer and loss. Mol. Biol. Evol. 37, 524-539 (2020).

18. Boxma, B. et al. An anaerobic mitochondrion that produces hydrogen. Nature 434, 74-79 (2005).

19. Embley, T. M. et al. Multiple origins of anaerobic ciliates with hydrogenosomes within the radiation of aerobic ciliates. Proc. R. Soc. Lond. B 262, 87-93 (1995).

20. Fenchel, T. \& Finlay, B. J. in (Endo)symbiotic Methanogenic Archaea (ed. Hackstein, J. H. P.) 1-11 (Springer, 2010).

21. Stairs, C. W., Leger, M. M. \& Roger, A. J. Diversity and origins of anaerobic metabolism in mitochondria and related organelles. Phil. Trans. R. Soc. Lond. B 370, 20140326 (2015).

22. Risgaard-Petersen, N. et al. Evidence for complete denitrification in a benthic foraminifer. Nature 443, 93-96 (2006).

23. Woehle, C. et al. A novel eukaryotic denitrification pathway in Foraminifera. Curr. Biol. 28, 2536-2543.e5 (2018).

24. Glock, N. et al. Metabolic preference of nitrate over oxygen as an electron acceptor in foraminifera from the Peruvian oxygen minimum zone. Proc. Natl Acad. Sci. USA 116, 2860-2865 (2019).

25. Shoun, H. \& Tanimoto, T. Denitrification by the fungus Fusarium oxysporum and involvement of cytochrome P-450 in the respiratory nitrite reduction. J. Biol. Chem. 266 11078-11082 (1991).

26. Kobayashi, M. et al. Denitrification, a novel type of respiratory metabolism in fungal mitochondrion. J. Biol. Chem. 271, 16263-16267 (1996).

27. Finlay, B., Span, A. \& Harman, J. Nitrate respiration in primitive eukaryotes. Nature $\mathbf{3 0 3}$ 333-336 (1983).

28. Dopheide, A., Lear, G., Stott, R. \& Lewis, G. Molecular characterization of ciliate diversity in stream biofilms. Appl. Environ. Microbiol. 74, 1740-1747 (2008).

29. Lynn, D. H. in The Ciliated Protozoa: Characterization, Classification, and Guide to the Literature (ed. Lynn, D. H.) 269-277 (Springer, 2008).

30. Boscaro, V. et al. EukRef-Ciliophora: a manually curated, phylogeny-based database of small subunit rRNA gene sequences of ciliates. Environ. Microbiol. 20, 2218-2230 (2018)

31. McCutcheon, J. P. \& Moran, N. A. Extreme genome reduction in symbiotic bacteria. Nat. Rev. Microbiol. 10, 13-26 (2012).

32. Moran, N. A. \& Bennett, G. M. The tiniest tiny genomes. Annu. Rev. Microbiol. 68, 195-215 (2014).

33. Zientz, E., Dandekar, T. \& Gross, R. Metabolic interdependence of obligate intracellular bacteria and their insect hosts. Microbiol. Mol. Biol. Rev. 68, 745-770 (2004).

34. Salem, H. et al. Drastic genome reduction in an herbivore's pectinolytic symbiont. Cell 171, 1520-1531.e13 (2017).

35. Grosser, K. et al. More than the "killer trait": infection with the bacterial endosymbiont Caedibacter taeniospiralis causes transcriptomic modulation in Paramecium host. Genome Biol. Evol. 10, 646-656 (2018).

36. Mendel, R. R. The molybdenum cofactor. J. Biol. Chem. 288, 13165-13172 (2013).

37. Graf, D. R., Jones, C. M. \& Hallin, S. Intergenomic comparisons highlight modularity of the denitrification pathway and underpin the importance of community structure for $\mathrm{N}_{2} \mathrm{O}$ emissions. PLoS ONE 9, e114118 (2014).

38. Kuypers, M. M. M., Marchant, H. K. \& Kartal, B. The microbial nitrogen-cycling network. Nat. Rev. Microbiol. 16, 263-276 (2018).

39. Major, P., Embley, T. M. \& Williams, T. A. Phylogenetic diversity of NTT nucleotide transport proteins in free-living and parasitic bacteria and eukaryotes. Genome Biol. Evol. 9, 480-487 (2017).

40. Schneider, R. E. et al. The Trichomonas vaginalis hydrogenosome proteome is highly reduced relative to mitochondria, yet complex compared with mitosomes. Int. J. Parasitol. 41, 1421-1434 (2011)

41. Gong, J. et al. Protist-bacteria associations: Gammaproteobacteria and Alphaproteobacteria are prevalent as digestion-resistant bacteria in ciliated protozoa. Front. Microbiol. 7, 498 (2016).

42. Fokin, S. I. \& Görtz, H.-D. in Endosymbionts in Paramecium (ed. Fujishima, M.) 161-199 (Springer, 2009).

43. Schweikert, M., Fujishima, M. \& Görtz, H.-D. in The Prokaryotes: Prokaryotic Biology and Symbiotic Associations (eds Rosenberg, E. et al.) 427-463 (Springer, 2013).

44. Chen, J. \& Strous, M. Denitrification and aerobic respiration, hybrid electron transport chains and co-evolution. Biochim. Biophys. Acta 1827, 136-144 (2013).

45. Quast, C. et al. The SILVA ribosomal RNA gene database project: improved data processing and web-based tools. Nucleic Acids Res. 41, D590-D596 (2013).

Funding Open access funding provided by Max Planck Society.

Publisher's note Springer Nature remains neutral with regard to jurisdictional claims in published maps and institutional affiliations.

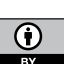

Open Access This article is licensed under a Creative Commons Attribution 4.0 International License, which permits use, sharing, adaptation, distribution and reproduction in any medium or format, as long as you give appropriate credit to the original author(s) and the source, provide a link to the Creative Commons license, and indicate if changes were made. The images or other third party material in this article are included in the article's Creative Commons license, unless indicated otherwise in a credit line to the material. If material is not included in the article's Creative Commons license and your intended use is not permitted by statutory regulation or exceeds the permitted use, you will need to obtain permission directly from the copyright holder. To view a copy of this license, visit http://creativecommons.org/licenses/by/4.0/.

(c) The Author(s) 2021 


\section{Methods}

No statistical methods were used to predetermine sample size. The experiments were not randomized, and investigators were not blinded to allocation during experiments and outcome assessment.

\section{Etymology}

The designation 'Azoamicus' combines the prefix azo- (New Latin, pertaining to nitrogen) with amicus (Latin, masculine noun, friend); thus giving azoamicus ('friend that pertains to nitrogen'), alluding to its role as denitrifying endosymbiont. 'Ciliaticola' combines ciliate (referring to a group of ciliated protozoa) with the suffix-cola (derived from the Latin masculine noun incola, dweller, inhabitant), thus meaning 'dwelling within a ciliate'.

\section{Geochemical profiling}

We carried out sampling for geochemical profiling in September 2016 and October 2018 at a single station located in the deep, southern lake basin of Lake Zug (about 197-m water depth) $\left(47^{\circ} 06^{\prime} 00.8^{\prime \prime} \mathrm{N}\right.$, $\left.8^{\circ} 29^{\prime} 35.0^{\prime \prime} \mathrm{E}\right)$. In September 2016, we used a multi-parameter probe to measure conductivity, turbidity, depth (pressure), temperature and pH (XRX 620, RBR). Dissolved oxygen was monitored online with normal and trace micro-optodes (types PSt1 and TOS7, Presens) with detection limits of 125 and $20 \mathrm{nM}$, respectively, and a response time of 7 s. In October 2018, we used a CTD (CTD60, Sea\&Sun Technology) equipped with a Clark-type oxygen sensor (accuracy $\pm 3 \%$, resolution $0.1 \%)$ to record oxygen profiles.

\section{Sample collection}

Water for bulk DNA and RNA analyses was collected in September 2016 and October 2018. Sample collection for DNA and RNA extraction in September 2016 has previously been described ${ }^{46}$. In October 2018, water was sampled with a Niskin bottle (Hydro-Bios) from $160 \mathrm{~m}, 170 \mathrm{~m}$ and $180 \mathrm{~m}$. For each depth, 2 l of lake water was directly filtered on board our boat onto 0.22- $\mu \mathrm{m}$ Sterivex filter cartridges (Merck Millipore) using a peristaltic pump, subsequently purged with RNAlater preservation solution (Life Technologies) and stored at $-20^{\circ} \mathrm{C}$ until further processing. For fluorescence in situ hybridization (FISH) analyses, water from the same depths was fixed on board the boat with formaldehyde (1.5\% final concentration; Electron Microscopy Sciences) and incubated in a chilled cool box for about $6 \mathrm{~h}$ before filtration onto $3-\mu \mathrm{m}$ polycarbonate filters (Merck Millipore). Additional FISH samples using the same approach were collected in May 2019 from 189 m water depth.

Water for incubation experiments and single-ciliate PCR was sampled in May 2019 from 189-m water depth using a 10 I Go-Flo bottle (General Oceanics), filled into 2.5 - I glass bottles without headspace, closed with butyl rubber stoppers and kept cold (at about $4{ }^{\circ} \mathrm{C}$ ) and dark until further handling. During sampling, oxygen contamination was minimized by overflowing the bottle with anoxic lake water.

For combined FISH and differential interference contrast microscopy analyses, individual live ciliates were picked from lake water (from 186-m depth, collected February 2020) and directly fixed on microscope slides. In brief, microscope slides were treated with $0.1 \mathrm{mg} \mathrm{ml}^{-1}$ poly-L-lysine for $10 \mathrm{~min}$ at room temperature, washed with MilliQ water and dried. Ciliates were pre-enriched by gravity flow of bulk lake water through a $5-\mu \mathrm{m}$ membrane filter and picked using a glass capillary under a binocular microscope. Picked ciliates were transferred into a droplet of formaldehyde ( $2 \%$ in $0.1 \times \mathrm{PBS}, \mathrm{pH} 7.6)$ on poly-L-lysine-coated microscope slides, incubated (for $1 \mathrm{~h}$ at room temperature) and washed with MilliQ water. FISH was performed as described in 'Double-labelled oligonucleotide probe fluorescence in situ hybridization and microscopy'.

\section{Nutrient measurements}

Water samples for measurements of nutrients (ammonium, $\mathrm{NO}_{x}$ and nitrite) were retrieved with a syringe sampler from 15 discrete depths at and below the base of the oxycline. Forty $\mathrm{ml}$ of water was directly injected into a 50-ml Falcon tube containing $10 \mathrm{ml}$ of OPA reagent for fluorometric ammonium quantification ${ }^{47}$. In 2018, ammonium concentration was determined using the same method, except that the lake water was immediately sterile-filtered after sampling and frozen at $-20^{\circ} \mathrm{C}$ until further processing. For $\mathrm{NO}_{x}$ quantification, $10 \mathrm{ml}$ of water was sterile-filtered into a $15-\mathrm{ml}$ Falcon tube and combined nitrate and nitrite concentration was determined by a commercial QuAAtro Segmented Flow Analyzer (SEAL Analytical).

\section{Clone library construction and Sanger sequencing}

'Candidatus A. ciliaticola'-specific 16S rRNA gene primers were designed on the basis of the ' $\mathrm{Ca}$. A. ciliaticola' circular metagenome-assembled genome sequence. Primers targeted the intergenic spacer regions about 50 bp up- and downstream of the 16S rRNA gene, resulting in a 1,568-bp-long PCR product. For clone library construction, the ' $\mathrm{Ca}$. A. ciliaticola' $16 \mathrm{~S}$ rRNA gene was amplified by a nested PCR approach from the same DNA extract used for metagenome sequencing obtained in September 2016 from 160-m water depth using the newly designed 'Ca.A. ciliaticola'-specific primers (eub62A3_29F and eub62A3_1547R) followed by PCR amplification with general bacterial $16 \mathrm{~S}$ rRNA gene primers (8F and 1492R) (Supplementary Table 2). Cloning and construction of the clone library is described in more detail in Supplementary Methods. Inserts of purified plasmids from five clones were sequenced by Sanger sequencing using the BigDye Terminator v.3.1 sequencing kit (Thermo Fisher Scientific) and primers M13f or M13r. The sequencing PCR contained $3 \mu \mathrm{l}$ purified plasmid, $0.5 \mu \mathrm{l} 10 \times$ sequencing buffer, $0.5 \mu \mathrm{l}$ primer $(10 \mu \mathrm{M})$ and $1 \mu \mathrm{l}$ BigDye reagent. The PCR reactions were performed as follows: 99 cycles $\left(1^{\circ} \mathrm{C} \mathrm{s}^{-1} \mathrm{ramp}\right)$ of denaturation (10 s at $96^{\circ} \mathrm{C}$ ), annealing $\left(5 \mathrm{~s}\right.$ at $\left.60^{\circ} \mathrm{C}\right)$ and elongation $\left(4 \mathrm{~min}\right.$ at $\left.60^{\circ} \mathrm{C}\right)$. The PCR products were purified using gel filtration (Sephadex G-50 Superfine, Amersham Bioscience) followed by Sanger sequencing (3130xl genetic analyser, Applied Biosystems). The Sanger sequences were quality-trimmed and assembled using Sequencher v.5.4.6 and standard settings before trimming vector and primer sequences.

\section{Probe design for fluorescence in situ hybridization}

To visualize ' $\mathrm{Ca}$. A. ciliaticola' cells in the environment, we designed a specific FISH probe on the basis of the ' $\mathrm{Ca}$. A. ciliaticola' circular metagenome-assembled genome $16 \mathrm{~S}$ rRNA gene sequence and closely related sequences within the clade eub62A3. The ' $\mathrm{C}$ a. A. ciliaticola' $16 \mathrm{~S}$ rRNA gene sequence was imported into $\mathrm{Arb}^{48} \mathrm{v} \cdot 6.1$ and aligned to the SILVA SSU Ref NR 99132 database using the SINA-Aligner ${ }^{49}$. A FISH probe specific for ' $\mathrm{C}$ a. A. ciliaticola' and most members of clade eub62A3 was designed (probe eub62A3_8135' CTAACAGCAAGTTTTCATCGTTTA3') (Supplementary Table 3) using the probe design tool implemented in Arb, and further manually refined and evaluated in silico using $\mathrm{MathFISH}^{50}$. The newly designed probe eub62A3_813 targets ' $\mathrm{Ca}$. A. ciliaticola' and $78 \%$ of the ' $\mathrm{Ca}$. Azoamicus' subgroup A and B sequences included in SILVA SSU Ref NR 99138 (7 out of 9; the 2 sequences that are not targeted belong to ' $\mathrm{C}$. Azoamicus' subgroup B), and shows no nontarget hits. Some sequences in the database had only 1 or 2 weak mismatches $(<0.5$ weighted mismatches) to the probe sequence. To ensure specificity in our FISH experiments and exclude the detection of nontarget organisms, we designed unlabelled competitor probes for these sequences with weak mismatches to the probe (competitor 1, 5' CTA ACAGCAAGTTCTCATCGTTTA 3 ' and competitor 2,5' CCAACAGCAAGTT CTCATCGTTTA 3') (Supplementary Table 3). These competitor probes were included in all FISH experiments (excluding clone-FISH). To further ensure that no nontarget organisms were present in our samples, we searched for $16 \mathrm{~S}$ rRNA gene reads with perfect matches against the eub62A3_813 probe sequence in one metagenome (Zug 2018,180 m). Almost all of the reads ( 82 out of 86 ) had $>98 \%$ identity with the $16 \mathrm{~S}$ rRNA gene sequence of ' $\mathrm{Ca}$. A. ciliaticola'. The remaining reads shared $>94 \%$ identity with ' $\mathrm{C} a$. A. ciliaticola' and all shared as top hits sequences 
belonging to ' $\mathrm{Ca}$. Azoamicus' subgroup A when blasted against the NCBI nr database (accessed June 2020).

\section{Clone-FISH}

Clone-FISH was performed as previously described ${ }^{51}$. In brief, a purified plasmid containing the ' $\mathrm{C} a$. A. ciliaticola' $16 \mathrm{~S}$ rRNA gene sequence (as described in 'Clone library construction and Sanger sequencing') in the correct orientation (confirmed by PCR using M13F and 1492R primers) was transformed into electrocompetent Escherichia coliJM109(DE3) cells (Promega) by electroporation using the Cell Porator and Voltage Booster System (Gibco) with settings $350 \mathrm{~V}, 330 \mu \mathrm{F}$ capacitance, low ohm impedance, fast charge rate and $4 \mathrm{k} \Omega$ resistance (Voltage Booster). After electroporation, cells were transferred into SOC medium (Sigma Aldrich), incubated for $1 \mathrm{~h}$ at $37^{\circ} \mathrm{C}$ and plated onto LB plates containing $100 \mathrm{mg} \mathrm{l}^{-1} \mathrm{kanamycin}$. After incubation overnight at $37^{\circ} \mathrm{C}, 4$ clones were picked and the presence of the insert was checked with PCR (primers M13F and 1492R) as described in 'Clone library construction and Sanger sequencing', followed by gel electrophoresis. An insert-positive clone was selected at random and grown in LB medium containing $100 \mathrm{mg} \mathrm{l}^{-1}$ kanamycin at $37^{\circ} \mathrm{C}$ until optical density at $600 \mathrm{~nm}$ reached 0.37. Transcription of the plasmid insert was induced using isopropyl $\beta$-D-1-thiogalactopyranoside (IPTG) (1 mM final concentration). After addition of IPTG, cells were incubated for $1 \mathrm{~h}$ at $37^{\circ} \mathrm{C}$ followed by addition of $170 \mathrm{mg} \mathrm{l}^{-1}$ chloramphenicol and subsequent incubation for $4 \mathrm{~h}$. Cells were collected by centrifugation, fixed in $2 \%$ formaldehyde solution for $1 \mathrm{~h}$ at room temperature, washed and stored at $4{ }^{\circ} \mathrm{C}$ in phosphate-buffered saline ( $\mathrm{pH} 7.4$ ) containing $50 \%$ ethanol until further processing. Formamide melting curves ${ }^{52}$ were carried out using a 'Ca.Azoamicus'-specific, HRP-labelled probe (eub62A3_813) (Extended Data Fig. 5). In brief, cells were applied to glass slides. Permeabilization with lysozyme, peroxidase inactivation, hybridization $(10 \%, 30 \%$, $35 \%, 40 \%, 45 \%$ and $50 \%$ formamide) and tyramide signal amplification (Oregon Green 488) was performed as previously described ${ }^{53}$. For each formamide concentration, images of three fields of view were recorded using the same exposure time for all formamide concentrations, which was optimized at $10 \%$ formamide all same settings using an Axio Imager 2 microscope (Zeiss) and analysed using Daime $2.1^{54}$.

\section{Double-labelled oligonucleotide probe fluorescence in situ hybridization and microscopy}

Hybridization with double-labelled oligonucleotide probes (terminally double-labelled with Atto488 dye; details of the probe are in Supplementary Table 3) (Biomers) and counterstaining with DAPI was performed as previously described ${ }^{55}$. In brief, samples (either cut filter sections or ciliates picked and fixed on a glass slide, as described in 'Sample collection') were incubated in hybridization buffer containing $25 \%$ formamide and $5 \mathrm{ng}$ DNA $\mu \mathrm{l}^{-1}$ probe (the same concentration was used for eub62A3_813 competitor 1 and 2 ) for $3 \mathrm{~h}$ at $46^{\circ} \mathrm{C}$, and subsequently washed in prewarmed washing buffer $(5 \mathrm{mM}$ EDTA, $159 \mathrm{mM}$ $\mathrm{NaCl}$ ) for $30 \mathrm{~min}$ at $48^{\circ} \mathrm{C}$. After a brief MilliQ water wash, samples were incubated for $5 \mathrm{~min}$ at room temperature in DAPI solution $\left(1 \mu \mathrm{g} \mathrm{ml}^{-1}\right)$, briefly washed in MilliQ water and air-dried. Filter sections were mounted onto glass slides. Samples were embedded in Prolong Gold Antifade Mountant (Thermo Fisher Scientific), and left to cure for $24 \mathrm{~h}$. Confocal laser scanning and differential interference contrast microscopy were performed on a Zeiss LSM 780 (Zeiss, 63× oil objective, 1.4 numerical aperture, with differential interference contrast prism).Z-stack images were obtained to capture entire ciliate cells and fluorescence images of FISH probe and DAPI signals were projected into 2D for visualization. Cell counting was performed using a Axio Imager 2 microscope (Zeiss) in randomly selected fields of view (40× objective, grid length $=312.5 \mu \mathrm{m})$ on polycarbonate filters $(3-\mu \mathrm{m}$ pore size, 32-mm effective filter diameter; Merck Millipore) onto which 0.5 IPFA-fixed lake water was filtered.
For light microscopy, live ciliates were picked from Lake Zug water (May 2019, $189 \mathrm{~m}$ ) and prepared for live ciliate imaging using light microscopy as previously described ${ }^{56}$ on an Axio Imager 2 microscope (Zeiss). For image acquisition and processing, Zeiss ZEN (blue edition) 2.3 was used.

\section{Scanning electron microscopy}

Ciliates sampled in February 2020 were individually picked under a binocular microscope, and washed in droplets of sterile-filtered lake water. Washed ciliates were then transferred into approximately $200 \mu \mathrm{l}$ fixative on top of a polylysine-coated silicon wafer $\left(0.1 \mathrm{mg} \mathrm{ml}^{-1}\right.$ poly-L-lysine for $10 \mathrm{~min}$ at room temperature) and fixed for $1 \mathrm{~h}$ at room temperature. The fixative contained $2.5 \%$ glutaraldehyde ( $\mathrm{v} / \mathrm{v}$, electron microscopy grade) in PHEM buffer ${ }^{57}$ ( $\mathrm{pH}$ 7.4). Fixed ciliates attached to the silicon wafer were dehydrated in an ethanol series (30\%, 50\%, 70\%, 80\%, 96\% and $100 \%$ ) before automated critical-point drying (EM CPD300, Leica). Scanning electron microscopy was performed on a Quanta FEG 250 (FEI). Images were obtained using FEI xTM v.6.3.6.3123 at an acceleration voltage of $2 \mathrm{kV}$ under high vacuum conditions and were captured using an Everhart-Thornley secondary electron detector. The image represents an integrated and drift corrected array of 128 images captured with a dwell time of $50 \mathrm{~ns}$.

\section{Single-ciliate PCR}

Ciliates were picked from Lake Zug water (189 m, 2019) under the binocular microscope with a glass micropipette, and subsequently washed twice in drops of sterile nuclease-free water (Ambion) before being transferred into lysis buffer. DNA was extracted using MasterPure DNA purification kit (Ambion) following the manufacturer's instructions with a final elution in $1 \times$ TE buffer $(25 \mu \mathrm{l})$. Overall, DNA was extracted from four individual ciliates (S1-S4), five (C5) and ten pooled ciliates $(\mathrm{C} 10)$ as well as no ciliate (control). $16 \mathrm{~S}$ (' $\mathrm{Ca}$. A. ciliaticola') and 18S rRNA gene sequences (ciliate host) were then separately amplified by PCR using primer pairs eub62A3_29F/_1547R and cil_384F/_1147R. PCR reactions $(20 \mu \mathrm{l})$ with ' $\mathrm{Ca}$. A. ciliaticola'-specific primers (eub62A3_29F/_1547R) were performed as described in 'Clone library construction and Sanger sequencing' with following modifications: $5 \mu$ template, $58^{\circ} \mathrm{C}$ annealing temperature and 40 amplification cycles. PCR with ciliate-specific primers (cil_384F/_1147R) was performed analogously with following modifications: $55^{\circ} \mathrm{C}$ annealing temperature, 50 s elongation and 35 amplification cycles. The PCR reactions with primer pairs eub62A3_29F/_1547R were further amplified in a second round of PCR (under the same conditions) using $2 \mu \mathrm{l}$ PCR reaction from the first round. For each PCR step, successful amplification of products was checked using gel electrophoresis as described in Supplementary Methods. PCR reactions were subsequently purified using QIAquick PCR purification Kit (Qiagen) according to the manufacturer's instructions with a final elution in sterile nuclease-free water $(25 \mu \mathrm{l})$ (Ambion). Purified PCR reactions were subsequently sequenced using Sanger sequencing and processed as described in 'Clone library construction and Sanger sequencing' with the following modifications: primers eub62A3_29F, eub62A3_1547R (annealing temperature $58^{\circ} \mathrm{C}$ ) or cil_384F, cil_1147R (annealing temperature $55^{\circ} \mathrm{C}$ ). Two of the single-ciliate DNA extracts amplified with the endosymbiont-specific primers either showed a faint (S4) or no (S2) band and were not sequenced.

\section{Nucleic acid extraction from lake water}

Bulk DNA and RNA extraction as well as metagenome and metatranscriptome sequencing of lake water samples collected in 2016 have previously been described ${ }^{46}$. For samples from 2018 , filters were purged of RNAlater, briefly rinsed with nuclease-free water and removed from the Sterivex cartridge. RNA and DNA was then extracted from separate filters using PowerWater RNA or DNA isolation kits (MoBio Laboratories) according to the manufacturer's instructions. 


\section{Metagenome and bulk metatranscriptome sequencing}

For metagenomic sequencing, DNA libraries were prepared as recommended by the NEBNext Ultra II FS DNA Library Prep Kit for Illumina (New England Biolabs). Sequencing-by-synthesis was performed on the Illumina HiSeq2500 sequencer (Illumina Inc.) with the $2 \times$ 250-bp read mode. For metatranscriptomic sequencing, rRNA was removed (Ribo-Zero rRNA Removal Kit for bacteria (Illumina)) and an RNA-sequencing library was prepared according to the NEBNext Ultra II Directional RNA Library Prep Kit for Illumina (New England Biolabs). Sequencing-by-synthesis was performed on the Illumina HiSeq3000 sequencer (Illumina) with the $1 \times 150$-bp read mode. Library preparation and sequencing was performed by the Max Planck Genome Centre Cologne (http://mpgc.mpipz.mpg.de/home/). Detailed information for each metagenomic and metatranscriptomic dataset can be found in Supplementary Table 4.

\section{Genome assembly and finishing}

The genome of ' $\mathrm{Ca}$. A. ciliaticola' was reconstructed from a metagenomic dataset sampled in 2018, as follows: metagenomic reads (MG_18_C) were trimmed using Trimmomatic ${ }^{58} \mathrm{v} .0 .32$ as previously described ${ }^{46}$ and assembled using metaSPAdes ${ }^{59}$ v.3.13.0 and $k$-mer lengths of 21, $33,55,77,99$ and 127 . From this assembly, contigs with high similarity to the previously reconstructed ' $\mathrm{Ca}$. A. ciliaticola' genome from the metagenome samples from 2016 (further details are provided in Supplementary Methods) were identified by blastn (identity $>95 \%$ ) and metagenomic reads were mapped back to the contigs using BBmap ${ }^{60}$ v.35.43 (minid $=0.98)$. Mapped reads were subsequently reassembled using SPAdes v.3.13.0 with mismatch corrector and coverage threshold enabled (--careful --cov-cutoff 60), resulting in the assembly of a single contig $(292,647 \mathrm{bp})$ that was circularized by trimming the identical overlapping ends (127 bp) giving rise to the closed genome (292,520 bp). The start position was set in an intergenic spacer region near the maximum of the GC disparity curve generated with oriFinder ${ }^{61} v \cdot 1.0$. The two independently assembled circular metagenome-assembled genomes (from 2016 and 2018 metagenomes (Supplementary Methods)) shared 99.99\% identity. For all subsequent analyses, the genome reconstructed from the 2018 dataset was used owing to higher coverage.

\section{Genome annotation and comparative analyses}

Genome annotation was performed using a modified version of Prokka ${ }^{62}$ v.1.13.3 to allow annotation of genes that overlap with tRNA genes. The annotation of key metabolic genes was manually inspected and refined using searches against NCBI non-redundant protein or conserved domain database ${ }^{63}$. Transmembrane transporters were predicted and classified using the Transporter Automatic Annotation Pipeline web service $^{64}$ and the Transporter Classification Database ${ }^{65}$. Pseudogenes were predicted using pseudo finder ${ }^{66} \mathrm{v} .0 .11$ and standard settings. Circular genome maps were created using DNAplotter ${ }^{67}$ v.18.1.0.

For comparative analyses, protein-coding CDS encoded in the genomes of insect endosymbionts ( $C$. ruddii PV, AP009180.1 and $B$. aphidicola BCc, CP000263.1), mitochondrion ofJ. libera (NC_021127) and a free-living relative of ' $\mathrm{C}$. A. Ailiaticola' ( $L$. clemsonensis, CP016397.1) were downloaded from NCBI GenBank. Additionally, protein-coding CDS of the ciliate endosymbiont $C$. taeniospiralis (PGGB00000000.1) were obtained using Prokka annotation. Classification of functional categories was performed using the eggNOG-mapper v.1 web service ${ }^{68}$ with mapping mode DIAMOND and standard settings. The classification of the functional category $C$ (energy production and conversion) for ' $\mathrm{C}$ a. A. ciliaticola' was modified to also include nor $B$ and nirK, which were grouped by eggNOG into different categories ( $Q$ and $P$, respectively).

Multiple sequence alignment of ' $\mathrm{C}$. A. ciliaticola' and other plastidic and bacterial ATP/ADP translocases was generated using MuscleWS ${ }^{69}$ v.3.8.31 with default settings implemented in Jalview ${ }^{70}$ v.2.11.1.0.

\section{Metatranscriptomic analyses of bulk water samples}

Raw metatranscriptomic Illumina reads trimming and removal of rRNA sequences was performed as previously described ${ }^{46}$. Non-rRNA reads were then mapped to the genome of ' $\mathrm{Ca}$. A. ciliaticola' using Bowtie $2^{71}$ v.2.2.1.0 and standard parameters. Sorted and indexed BAM files were generated using samtools ${ }^{72} \mathrm{v} \cdot 0.1 .19$ and transcripts per feature (based on the Prokka annotation) were quantified using EDGE-pro ${ }^{73} \mathrm{v} \cdot 1.3 .1$ and standard settings. Gene transcription was subsequently quantified as transcripts per million ${ }^{74}$ (TPM) using the formula:

$$
\mathrm{TPM}_{\mathrm{i}}=\frac{c_{i}}{l_{i}} \times \frac{1}{\sum_{j} \frac{c_{i}}{l_{i}}} \times 10^{6}
$$

to assign each feature $(i)$ a TPM value, in which $c=$ feature count, $l=$ length (in $\mathrm{kb}$ ) and $j=$ all features.

Read coverage visualization and plotting was performed using pyGenomeTracks ${ }^{75}$ (average coverage over 100-bp bins) implemented in deepTools $2^{76}$ v.3.2.0.

\section{Phylogenetic analyses}

The full-length $16 \mathrm{~S}$ rRNAgene sequence was retrieved from the circular metagenome-assembled genome of ' $\mathrm{C} a$. A. ciliaticola' using RNAmmer ${ }^{77}$ v.1.5, aligned using the SILVA incremental aligner ${ }^{49}$ (SINA 1.2.11) and imported to the SILVA SSU NR99 database ${ }^{45}$ (release 132) using ARB ${ }^{48}$ v.6.1. Additional closely related $16 \mathrm{~S}$ rRNA gene sequences were identified by BLASTN in the NCBI non-redundant nucleotide database and JGI IMG/M 16S rRNA Public Assembled Metagenomes (retrieved July 2018) and also imported into ARB. A maximum-likelihood phylogenetic tree of $16 \mathrm{~S}$ rRNA gene sequences was calculated using $\mathrm{RAxML}^{78}$ v.8.2.8 integrated in ARB with the GAMMA model of rate heterogeneity and the GTR substitution model with 100 bootstraps. The alignment was not constrained by a weighting mask or filter. For the complete tree shown in Extended Data Fig. 4, additional ' $\mathrm{C}$. A. ciliaticola' sequences obtained from a clone library and individual single ciliates were added to the tree using the Parsimony 'Quick add' algorithm implemented in ARB.

For the ciliate phylogeny, sequences obtained from Sanger sequencing of picked ciliates were added to the EukRef-Ciliphora ${ }^{30}$ Plagiopylea subgroup alignment using MAFFT ${ }^{79}$ online service version 7 (argument:-addfragments). An additional metagenome-assembled full-length 18S rRNA gene sequence assigned to Plagiopylea was obtained using phyloFlash ${ }^{80}$ v.3.0 from one of the Lake Zug metagenomes (MG_18_C) and also added to the alignment (argument:--add). A phylogenetic tree was calculated using IQ-TREE webserver (http://iqtree.cibiv.univie. ac.at) running IQ-TREE ${ }^{81} 1.6 .11$ with default settings and automatic substitution model selection (best-fit model: TIM2+F+I+G4). Phylogenetic trees were visualized using the Interactive Tree of Life v. 4 web service ${ }^{82}$.

For the ATP/ADP translocase phylogenetic tree, amino acid sequences were retrieved from NCBI RefSeq (250 top hits) and NCBI nr (15 top hits) (both accessed June 2019) using NCBI blastp web-service ${ }^{83}$ with the amino acid sequence of ATP/ADP translocase sequence of ' $\mathrm{Ca}$. A. ciliaticola' (ESZ_00147) as query. Additional amino acid sequences of characterized nucleotide transporters listed in Supplementary Table 8 were also added. After removal of duplicates, sequences were clustered at $95 \%$ identity using usearch ${ }^{84}$ v.8.0.1623 and aligned using MUSCLE ${ }^{69}$ v.3.8.31. Phylogenetic tree construction using IQ-TREE (best-fit model: $\mathrm{LG}+\mathrm{F}+\mathrm{I}+\mathrm{G} 4)$ and visualization was performed as described for the $18 \mathrm{~S}$ rRNA gene phylogenetic tree.

\section{Incubation experiments}

Incubation experiments were performed to provide experimental evidence for the denitrifying activity linked to the ciliate host. Three incubations were set up that contained (a) no ciliates (filtered fraction), (b) lake water that was enriched in ciliates (enriched fraction) and (c) bulk lake water. For these experiments, lake water was size-fractionated 
using a 10 - $\mu \mathrm{m}$ polycarbonate filter (Merck Millipore) under $\mathrm{N}_{2}$ atmosphere in a glove bag at $12{ }^{\circ} \mathrm{C}$. Enriched and filtered fractions were obtained by gravity filtration of 0.51 water until 0.251 supernatant was left. Thus, in the enriched fraction, ciliates from $0.5 \mathrm{I}$ lake water were concentrated in 0.25 I lake water. In the filtered fraction, organisms larger than $10 \mu \mathrm{m}$ (including ciliates) were filtered out. Both the enriched water (plus filter) and the filtered water were transferred to separate serum bottles (no headspace) and closed with butyl rubber stoppers. For bulk incubations, unfiltered water was directly filled into $250 \mathrm{ml}$ serum bottles under $\mathrm{N}_{2}$ atmosphere.

Denitrification potential was assessed by measuring the production of ${ }^{30} \mathrm{~N}_{2}$ over time in ${ }^{15} \mathrm{~N}$-nitrite and ${ }^{15} \mathrm{~N}$-nitrate amended incubations by isotope ratio mass spectrometry (Isoprime Precision running ionOS v.4.04, Elementar). A $30 \mathrm{ml}$ helium headspace was set for the $250 \mathrm{ml}$ serum bottles and the water was degassed with helium for $10 \mathrm{~min}$ to ensure anoxic conditions and reduce $\mathrm{N}_{2}$ background. $\mathrm{A}^{15} \mathrm{~N}$-labelled mixture of nitrate and nitrite $(20 \mu \mathrm{M}$ and $5 \mu \mathrm{M}$ final concentration, respectively; Sigma Aldrich) was supplied at a $99 \%$ labelling percentage and the water was incubated for a total of $30 \mathrm{~h}$ at $4{ }^{\circ} \mathrm{C}$ in the dark. Subsamples of the headspace were taken at regular time intervals during the incubation by withdrawing $3 \mathrm{ml}$ of the gaseous headspace and simultaneously replacing the removed volume by helium. This gas sample was transferred into $12 \mathrm{ml}$ Exetainers (LabCo) that were pre-filled with helium-degassed water and stored until analysis. ${ }^{30} \mathrm{~N}_{2}$ in the gas samples was measured on an isotope ratio mass spectrometer, and denitrification rates were calculated from the slope of the linear increase of ${ }^{30} \mathrm{~N}_{2}$ in the headspace over the time course of the experiments. The rate of ${ }^{30} \mathrm{~N}_{2}$ production was corrected for dilution of the headspace introduced by subsampling and by the measured total ${ }^{15} \mathrm{~N}$ labelling percentage. ' $\mathrm{Ca}$. A. ciliaticola'-containing ciliate abundance in the different incubation bottles was assessed by microscopic counts after cell fixation, FISH hybridization (eub62A3_813) and DAPI staining as described in 'Double-labelled oligonucleotide probe fluorescence in situ hybridization and microscopy'.

\section{Statistics and reproducibility}

No statistical methods were used to predetermine sample size and experiments were not randomized. The investigators were not blinded to allocation during experiments and outcome assessment.

In Fig. 1a, the scanning electron microscopy image is a representative of $n=6$ recorded images that were obtained from 1 experiment. In Fig $1 b$, the differential interference contrast image is a representative of $n=6$ recorded images that were obtained from 1 experiment.

In Fig. 2c, Extended Data Fig. 2i. FISH fluorescence images (eub62A3_813 probe) are representative of $n=33$ recorded images that were obtained from 5 independent experiments of 3 biological replicate samples.

In Fig. 2c, Extended Data Fig. 2f, h, j. DAPI fluorescence images are representative of $n=21$ recorded images that were obtained from 5 independent experiments of 3 biological replicate samples.

In Extended Data Fig. 2a, the FISH fluorescence image (Arch915 probe) is representative of $n=6$ images that were obtained from 1 experiment. In Extended Data Fig. $2 \mathrm{~b}, \mathrm{~d}, \mathrm{~F}_{420}$ autofluorescence images are representative of $n=11$ recorded images that were obtained from 3 independent experiments of 1 sample. In Extended Data Fig. 2c, g, FISH fluorescence images (EUB-I probe) are representative of $n=15$ images obtained from 3 independent experiments of 2 biological replicate samples. In Extended Data Fig. 2e, the FISH fluorescence image (NON338 probe) is representative of $n=15$ recorded images that were obtained from 3 independent experiments of 2 biological replicate samples.

In Extended Data Fig. 5a, each of the 6 FISH fluorescence images (eub62A3_813 probe) is representative of $n=3$ images from 1 experiment.

For the fluorescence images shown, the number of analysed cells was typically much higher $(n>100)$ than the ones that were eventually recorded.

\section{Reporting summary}

Further information on research design is available in the Nature Research Reporting Summary linked to this paper.

\section{Data availability}

The annotated genome of ' $\mathrm{Ca}$. A. ciliaticola' has been deposited at the European Nucleotide Archive (ENA) under the BioProject PRJEB27314 (accession number LR794158). Small-subunit rRNA gene sequences of 'Ca. A. ciliaticola' and the plagiopylean host have been deposited at ENA under BioProject PRJEB27314 and accession numbers LR798074LR798089. Raw metagenomic and metatranscriptomic sequencing data of bulk water samples as well as single-ciliate transcriptomes have been deposited at ENA under BioProject PRJEB36502 using the data brokerage service of the German Federation for Biological Data (GFBio) ${ }^{85}$. Metatranscriptomic sequencing data obtained in the year 2016 have previously been deposited at the Sequence Read Archive under BioProject PRJNA401219. Publicly available sequences used for phylogenetic trees are available under their respective accession codes at the SILVA rRNA database (http://www.arb-silva.de/) (Fig. 2e, Extended Data Fig. 4), JGI Integrated Microbial Genomes and Microbiomes database (http://img.jgi.doe.gov/) (Fig. 2e), EukRef-Ciliophora database (https:// github.com/eukref/curation) (Fig. 2f), orthoDB (http://www.orthodb. org/) (Extended Data Fig. 6) and NCBI protein database (http://www. ncbi.nlm.nih.gov/protein/) (Extended Data Figs. 9,10). Genomes used for comparative analyses are available under their respective accession codes at NCBI (http://www.ncbi.nlm.nih.gov/genome/) (Fig. 2b, c). Transporter classification information (Supplementary Table 6) can be found at the Transporter Classification Database (http://www.tcdb. org/). Source data are provided with this paper.

46. Graf, J. S. et al. Bloom of a denitrifying methanotroph, 'Candidatus Methylomirabilis limnetica', in a deep stratified lake. Environ. Microbiol. 20, 2598-2614 (2018).

47. Holmes, R. M., Aminot, A., Kérouel, R., Hooker, B. A. \& Peterson, B. J. A simple and precise method for measuring ammonium in marine and freshwater ecosystems. Can. J. Fish. Aquat. Sci. 56, 1801-1808 (1999).

48. Ludwig, W. et al. ARB: a software environment for sequence data. Nucleic Acids Res. 32 , 1363-1371 (2004).

49. Pruesse, E., Peplies, J. \& Glöckner, F. O. SINA: accurate high-throughput multiple sequence alignment of ribosomal RNA genes. Bioinformatics 28, 1823-1829 (2012).

50. Yilmaz, L. S., Parnerkar, S. \& Noguera, D. R. mathFISH, a web tool that uses thermodynamics-based mathematical models for in silico evaluation of oligonucleotide probes for fluorescence in situ hybridization. Appl. Environ. Microbiol. 77, 1118-1122 (2011).

51. Schramm, A., Fuchs, B. M., Nielsen, J. L., Tonolla, M. \& Stahl, D. A. Fluorescence in situ hybridization of $16 \mathrm{~S}$ rRNA gene clones (Clone-FISH) for probe validation and screening of clone libraries. Environ. Microbiol. 4, 713-720 (2002).

52. Manz, W., Amann, R., Ludwig, W., Wagner, M. \& Schleifer, K.-H. Phylogenetic oligodeoxynucleotide probes for the major subclasses of Proteobacteria: problems and solutions. Syst. Appl. Microbiol. 15, 593-600 (1992).

53. Pernthaler, A., Pernthaler, J. \& Amann, R. Fluorescence in situ hybridization and catalyzed reporter deposition for the identification of marine bacteria. Appl. Environ. Microbiol. 68, 3094-3101 (2002).

54. Daims, H., Lücker, S. \& Wagner, M. daime, a novel image analysis program for microbial ecology and biofilm research. Environ. Microbiol. 8, 200-213 (2006).

55. Glöckner, F. O. et al. An in situ hybridization protocol for detection and identification of planktonic bacteria. Syst. Appl. Microbiol. 19, 403-406 (1996).

56. Foissner, W. An update of 'basic light and scanning electron microscopic methods for taxonomic studies of ciliated protozoa'. Int. J. Syst. Evol. Microbiol. 64, 271-292 (2014).

57. Schliwa, M. \& van Blerkom, J. Structural interaction of cytoskeletal components. J. Cell Biol. 90, 222-235 (1981)

58. Bolger, A. M., Lohse, M. \& Usadel, B. Trimmomatic: a flexible trimmer for Illumina sequence data. Bioinformatics 30, 2114-2120 (2014).

59. Nurk, S., Meleshko, D., Korobeynikov, A. \& Pevzner, P. A. metaSPAdes: a new versatile metagenomic assembler. Genome Res. 27, 824-834 (2017).

60. Bushnell, B. BBMap, http://sourceforge.net/projects/bbmap (2016).

61. Gao, F. \& Zhang, C.-T. Ori-Finder: a web-based system for finding oriCs in unannotated bacterial genomes. BMC Bioinformatics 9, 79 (2008).

62. Seemann, T. Prokka: rapid prokaryotic genome annotation. Bioinformatics $\mathbf{3 0}$, 2068-2069 (2014).

63. Marchler-Bauer, A. et al. CDD: NCBI's conserved domain database. Nucleic Acids Res. 43, D222-D226 (2015).

64. Elbourne, L. D. H., Tetu, S. G., Hassan, K. A. \& Paulsen, I. T. TransportDB 2.O: a database for exploring membrane transporters in sequenced genomes from all domains of life. Nucleic Acids Res. 45, D320-D324 (2017). 
65. Saier, M. H., Jr et al. The Transporter Classification Database (TCDB): recent advances. Nucleic Acids Res. 44, D372-D379 (2016).

66. Syberg-Olsen, M., Garber, A., Keeling, P., McCutcheon, J. \& Husnik, F. Pseudofinder, https://github.com/filip-husnik/pseudofinder/ (2020).

67. Carver, T., Thomson, N., Bleasby, A., Berriman, M. \& Parkhill, J. DNAPlotter: circular and linear interactive genome visualization. Bioinformatics 25, 119-120 (2009).

68. Huerta-Cepas, J. et al. eggNOG 4.5: a hierarchical orthology framework with improved functional annotations for eukaryotic, prokaryotic and viral sequences. Nucleic Acids Res. 44, D286-D293 (2016).

69. Edgar, R. C. MUSCLE: multiple sequence alignment with high accuracy and high throughput. Nucleic Acids Res. 32, 1792-1797 (2004).

70. Waterhouse, A. M., Procter, J. B., Martin, D. M. A., Clamp, M. \& Barton, G. J. Jalview Version 2-a multiple sequence alignment editor and analysis workbench. Bioinformatics $\mathbf{2 5}$, 1189-1191 (2009).

71. Langmead, B. \& Salzberg, S. L. Fast gapped-read alignment with Bowtie 2. Nat. Methods 9, 357-359 (2012).

72. Li, H. et al. The Sequence Alignment/Map format and SAMtools. Bioinformatics 25, 2078-2079 (2009).

73. Magoc, T., Wood, D. \& Salzberg, S. L. EDGE-pro: estimated degree of gene expression in prokaryotic genomes. Evol. Bioinform. 9, 127-136 (2013).

74. Wagner, G. P., Kin, K. \& Lynch, V. J. Measurement of mRNA abundance using RNA-seq data: RPKM measure is inconsistent among samples. Theory Biosci. 131, 281-285 (2012).

75. Ramírez, F. et al. High-resolution TADs reveal DNA sequences underlying genome organization in flies. Nat. Commun. 9, 189 (2018).

76. Ramírez, F. et al. deepTools2: a next generation web server for deep-sequencing data analysis. Nucleic Acids Res. 44, W160-W165 (2016).

77. Lagesen, K. et al. RNAmmer: consistent and rapid annotation of ribosomal RNA genes. Nucleic Acids Res. 35, 3100-3108 (2007).

78. Stamatakis, A. RAxML version 8: a tool for phylogenetic analysis and post-analysis of large phylogenies. Bioinformatics 30, 1312-1313 (2014).

79. Katoh, K., Rozewicki, J. \& Yamada, K. D. MAFFT online service: multiple sequence alignment, interactive sequence choice and visualization. Brief. Bioinform. 20, 1160-1166 (2019).

80. Gruber-Vodicka, H. R., Seah, B. K. B. \& Pruesse, E. phyloFlash: rapid small-subunit rRNA Profiling and targeted assembly from metagenomes. mSystems 5, e00920-20 (2020).

81. Trifinopoulos, J., Nguyen, L.-T., von Haeseler, A. \& Minh, B. Q. W-IQ-TREE: a fast online phylogenetic tool for maximum likelihood analysis. Nucleic Acids Res. 44, W232-W235 (2016).

82. Letunic, I. \& Bork, P. Interactive Tree Of Life (iTOL) v4: recent updates and new developments. Nucleic Acids Res. 47, W256-W259 (2019).
83. Camacho, C. et al. BLAST+: architecture and applications. BMC Bioinformatics 10, 421 (2009).

84. Edgar, R. C. Search and clustering orders of magnitude faster than BLAST. Bioinformatics 26, 2460-2461 (2010).

85. Diepenbroek, M. et al. in Informatik 2014-Big Data Komplexität Meistern (eds. Plödereder, E. et al.) 1711-1724 (Köllen, 2014).

86. Trentmann, O., Decker, C., Winkler, H. H. \& Neuhaus, H. E. Charged amino-acid residues in transmembrane domains of the plastidic ATP/ADP transporter from Arabidopsis are important for transport efficiency, substrate specificity, and counter exchange properties. Eur. J. Biochem. 267, 4098-4105 (2000).

Acknowledgements We thank the Swiss Federal Institute of Aquatic Science and Technology (Eawag) for the use of its boat, housing and research facilities; A. Zwyssig, C. Dinkel and K. Beck for their help during field trips; V. Hübner, D. Tienken, N. Rujanski and G. Lavik for technical support; N. Lehnen, A. Gruhl and S. Littmann for support with microscopy; H. Marchant, B. Kartal and B. Barker Jørgensen for helpful discussions and comments on the manuscript; K. Koren for providing oxygen-sensitive nanoparticles; and L. van Niftrik and R. Mesman for their effort in preparing samples for TEM. This study was financially supported by the Max Planck Gesellschaft and internal funds of Eawag.

Author contributions J.S.G. reconstructed the genome of ' $\mathrm{C}$. A. ciliaticola', performed genomic, metagenomic, transcriptomic and phylogenetic analyses, single ciliate PCR and FISH analyses, and scanning electron microscopy sample preparation and imaging; J.S.G. and C.W. analysed single ciliate transcriptome data; S.S. carried out incubations and performed data analysis; K.K. designed primers and FISH probes; J.S.G. and K.K. constructed clone libraries and performed clone-FISH; S.S. and S.A. designed and performed chemotaxis assays; B.H. constructed and sequenced metagenomic, bulk water metatranscriptomic and single ciliate transcriptome libraries, J.S.G., S.S., C.J.S., M.M.M.K. and J.M. organized and carried out sampling and characterized environmental samples; J.S.G., M.M.M.K. and J.M. designed the study, analysed data and wrote the manuscript with contributions from all other authors.

Competing interests The authors declare no competing interests.

\section{Additional information}

Supplementary information The online version contains supplementary material available at https://doi.org/10.1038/s41586-021-03297-6.

Correspondence and requests for materials should be addressed to J.S.G. or J.M.

Peer review information Nature thanks Thijs Ettema, Michael Ryan, Andreas Schramm and Marc Strous for their contribution to the peer review of this work.

Reprints and permissions information is available at http://www.nature.com/reprints. 


\section{Article}

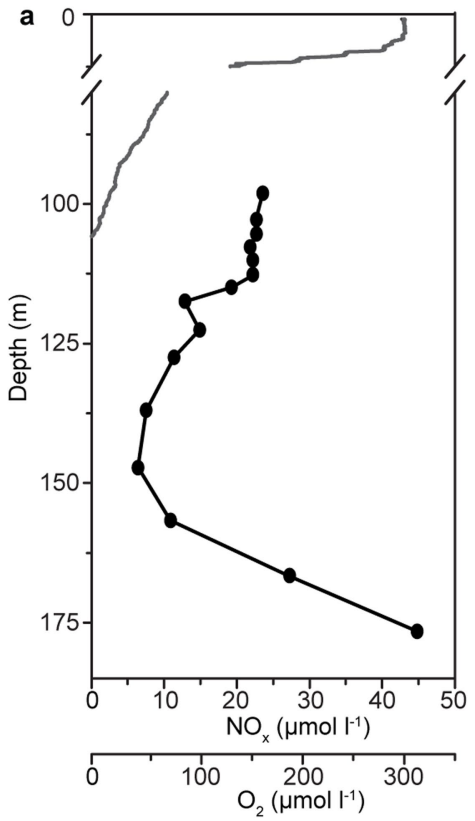

Extended Data Fig. 1 | Lake Zug physicochemical profiles and abundance of ciliates containing ' $\boldsymbol{C a}$. A. ciliaticola'. a, b, Depth profiles of oxygen and $\mathrm{NO}_{x}$ (nitrate + nitrite) throughout the lower water column of Lake Zug measured in 2016 (a) and 2018 (b). In 2018, the abundance of ciliates containing ' $C a$. A. ciliaticola' (shown as grey bars in $\mathbf{b}$ ) from immediately below the base of the

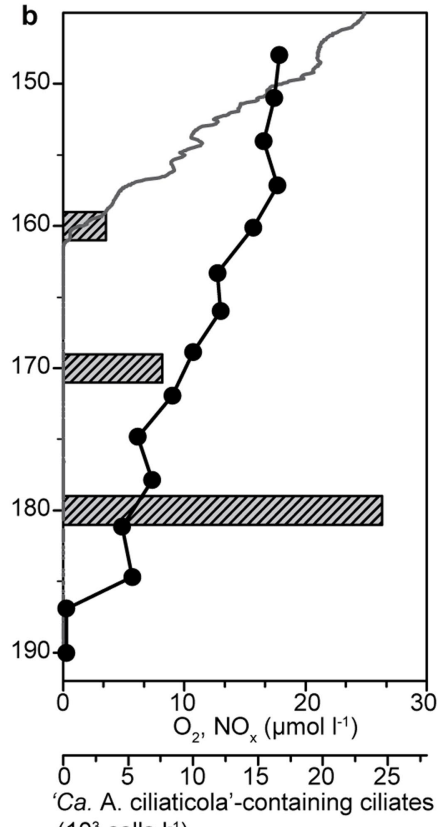

$\left(10^{3}\right.$ cells $\left.^{-1}\right)$

oxycline $(160 \mathrm{~m})$ was $3.2 \times 10^{3}$ cells per litre $(n=29$ cells), which corresponds to approximately half of all unicellular eukaryotes at this depth. At $180 \mathrm{~m}$, all investigated eukaryotes were ciliates that contain ' $\mathrm{Ca}$. A. ciliaticola', and their abundance had increased to $24.5 \times 10^{3}$ cells per litre ( $n=77$ cells $)$ (Supplementary Table1). 

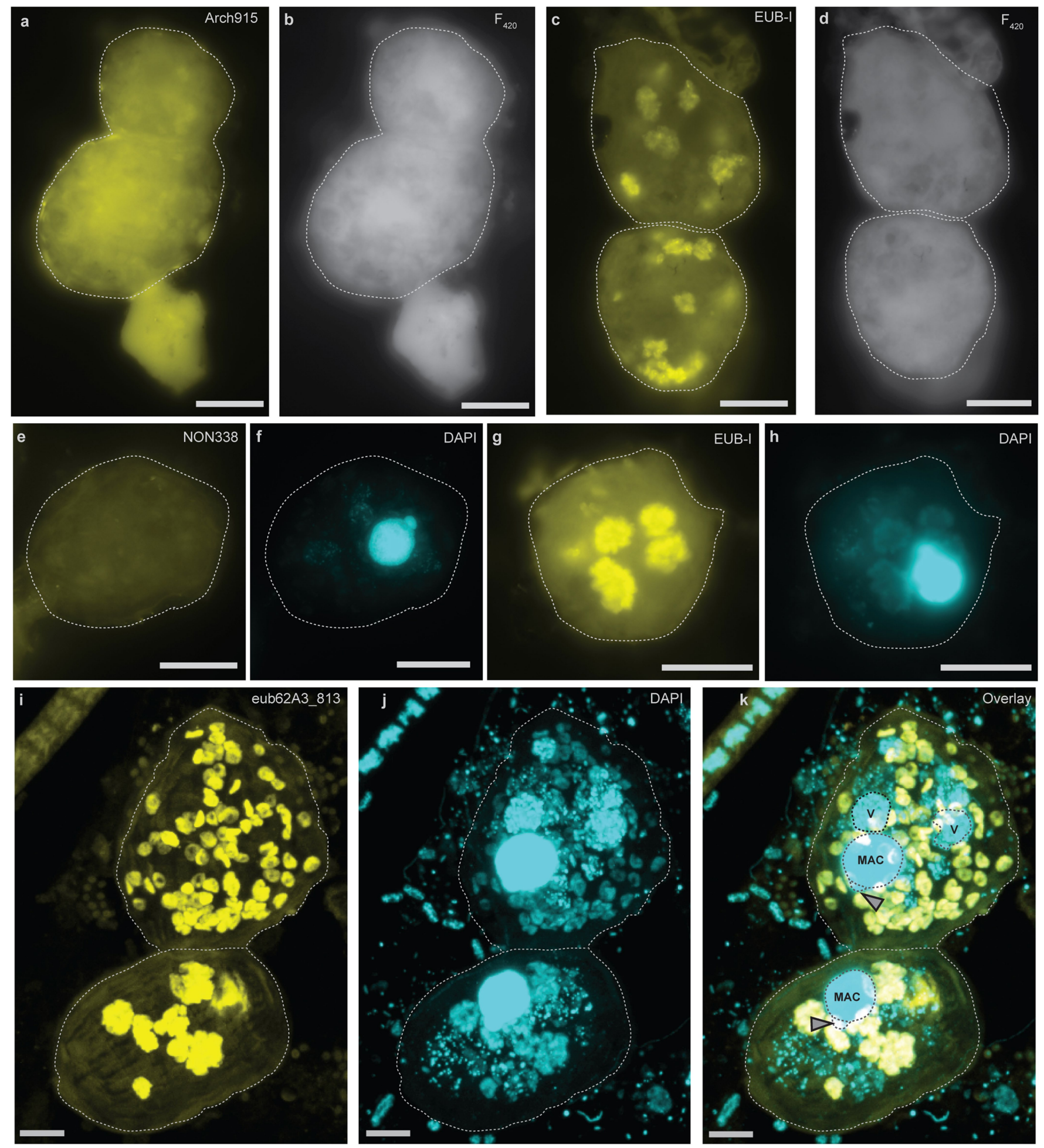

Extended Data Fig. 2 | Fluorescence images of ciliates from Lake Zug. a-e, g, Epifluorescence images of ciliates from Lake Zug $(2018,180 \mathrm{~m})$ after hybridization with a general probe for archaea (a) (Arch915), most bacteria (c, g) (EUB-I) and a negative control (e) (NON338). $\mathrm{F}_{420}$ autofluorescence $(\mathbf{b}, \mathbf{d})$ (in grey-scale) and Arch 915 probe (a) images did not show discrete signals indicative of endosymbiotic methanogenic archaea. By contrast, clear signals of intracellular bacteria (endosymbiotic or in food vacuoles) are visible with the EUB-I probe $(\mathbf{c}, \mathbf{g}) . \mathbf{f}, \mathbf{h}, \mathbf{j}$, DAPI images show presence of macronucleus and micronucleus as well as endosymbionts. $\mathbf{i}-\mathbf{k}$, Confocal laser scanning microscopy images of two ciliates after hybridization with ' $\mathrm{Ca}$.
Azoamicus'-specific oligonucleotide probe (eub62A3_813) (yellow) and counterstaining with DAPI (cyan). Overlay (k) and individual channels (eub62A3_813 (i) and DAPI (j)) from the same field of view; fluorescence images from a $z$-stack were projected into $2 \mathrm{D}$ for visualization. Two morphotypes of ' $C a$. A. ciliaticola' are visible on the images: evenly distributed ovoid cells (1.5-2- $\mu \mathrm{m}$ long) and densely packed, irregular clusters (3-10- $\mu \mathrm{m}$ diameter) of cells. The macronucleus (MAC) with attached micronucleus (grey arrow) and putative food vacuoles (V) of the ciliate are outlined in the overlay image (k). In all images, ciliate cells are outlined with grey dotted lines (corresponding fields of view in $\mathbf{~}$ and $\mathbf{b} ; \mathbf{c}$ and $\mathbf{d} ; \mathbf{e}$ and $\mathbf{f} ; \mathbf{g}$ and $\mathbf{h}$; and $\mathbf{i}$ and $\mathbf{k}$ ). Scale bars, $5 \mu \mathrm{m}$. 


\section{Article}

a
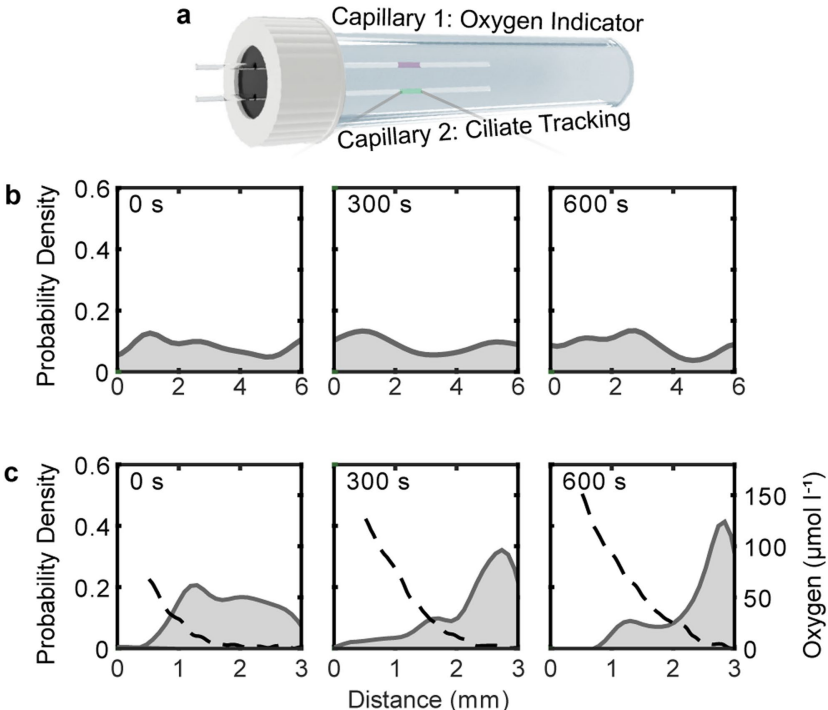

Extended Data Fig. 3 | Negative aerotactic behaviour of ciliate hosts exposed to varying concentrations of oxygen. a, Schematic of a two-capillary experimental setup that allows for simultaneous oxygen measurements and ciliate tracking. b, Reference experiment showing the positioning of ciliates under anoxic conditions on the basis of 3 measurements after $0 \mathrm{~s}, 300 \mathrm{~s}$ and $600 \mathrm{~s}$. The positioning is expressed as probability density and is defined as the percentage of the ciliates at a specific distance to the anoxic bubble. c, Chemotaxis experiments in which ciliates were exposed to a gradient of increasing oxygen concentration. These data were extracted from the video in Supplementary Video 2 with simultaneous ciliate tracking and oxygen concentration determination. 


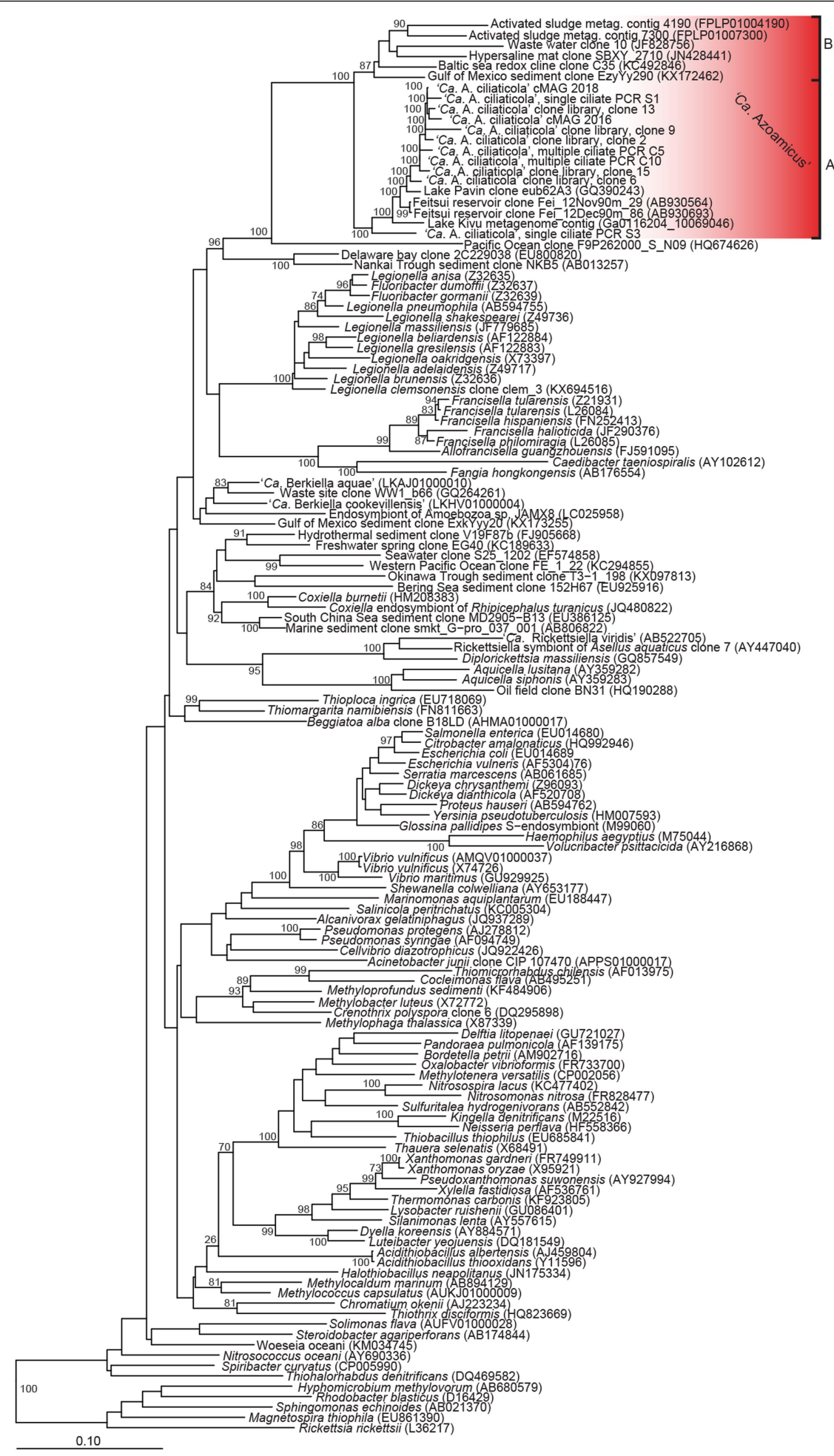

Extended Data Fig. 4 | Phylogenetic affiliation of ' $\mathrm{Ca}$. A. ciliaticola' within the Gammaproteobacteria. $16 \mathrm{~S}$ rRNAgene sequence-based maximumlikelihood phylogenetic tree of ' $\mathrm{C}$. A. ciliaticola' and other members of the Gammaproteobacteria. The circular metagenome-assembled genome-derived 16S rRNA gene sequences (cMAG 2016 and cMAG 2018) (details are provided in Supplementary Discussion), as well as ' $C a$. A. ciliaticola' Sanger sequences retrieved from a clone library (clones 2, 6, 9,13 and 15; details are provided in Methods), and amplified from individual (S1 and S3) or combined ciliates
(C5 and C10), were included in the tree. 'Candidatus Azoamicus' subgroup A and $B$ are highlighted in red. Four sequences belonging to the Alphaproteobacteria served as outgroup (Rickettsia rickettsia, L36217; Magnetospira thiophila, $\mathrm{AB021370;} \mathrm{Hyphomicrobium} \mathrm{methylovorum,}$ AB680579; and Rhodobacter blasticus, D16429). Bootstrap values $>70 \%$ (out of 100 resamplings) are shown in front of the respective nodes, and the scale bar indicates nucleotide substitutions per site. 


\section{Article}

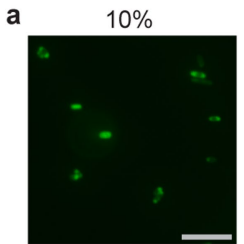

$40 \%$
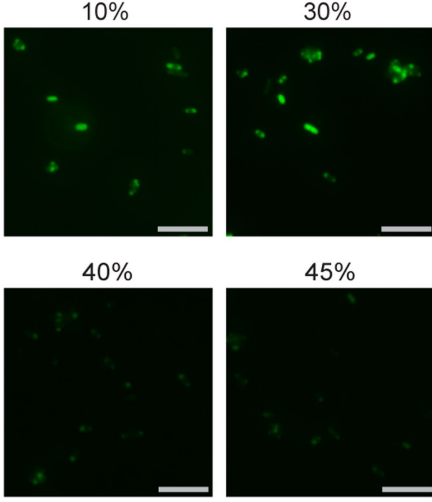

$45 \%$
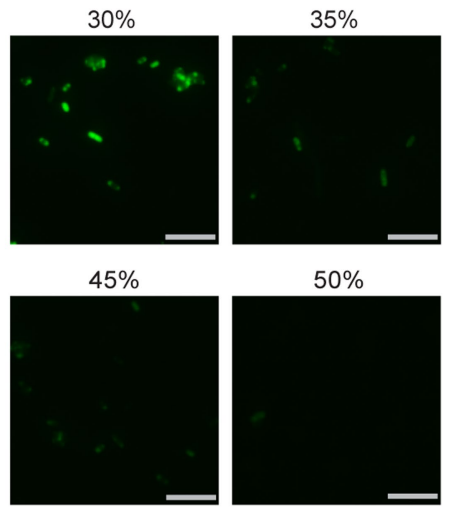

b

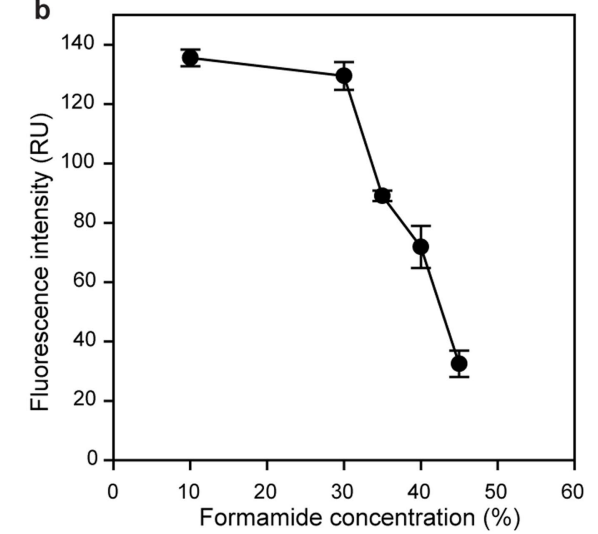

eub62A3_813. Centre values show average fluorescence intensity and error bars represent s.e. $(10 \%, n=28$ cells; $30 \%, n=22$ cells; $35 \%, n=26$ cells; $40 \%$, $n=10$ cells; $45 \%, n=4$ cells). The fluorescence intensity of cells hybridized at $50 \%$ formamide could not be determined owing to the low intensity, and was therefore not included in the formamide melting curve. gene of ' $\mathrm{C}$. A. ciliaticola' hybridized at different formamide concentrations $(10 \%, 30 \%, 35 \%, 40 \%, 45 \%$ and $50 \%)$ with ' $\mathrm{C}$ a. A. ciliaticola'-specific probe eub62A3_813. Scale bar, $10 \mu \mathrm{m}$. b. Formamide melting curve for probe

Extended Data Fig. 5 | eub62A3_813 FISH probe optimization using clone-FISH. a, Fluorescence pictures of $E$. coli cells transcribing the 16 S rRNA 
a Phenylalanyl-tRNA synthetase, B3/B4 (10862at33630)

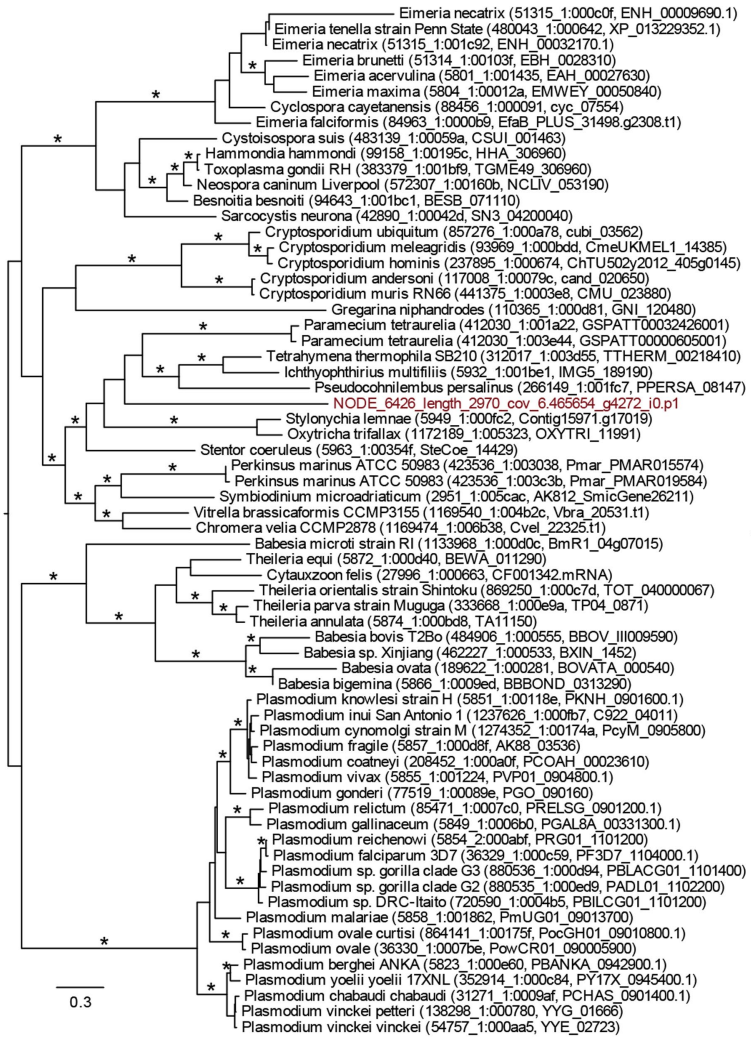

b Ribosomal protein L30, ferredoxin-like fold domain (29724at33630)

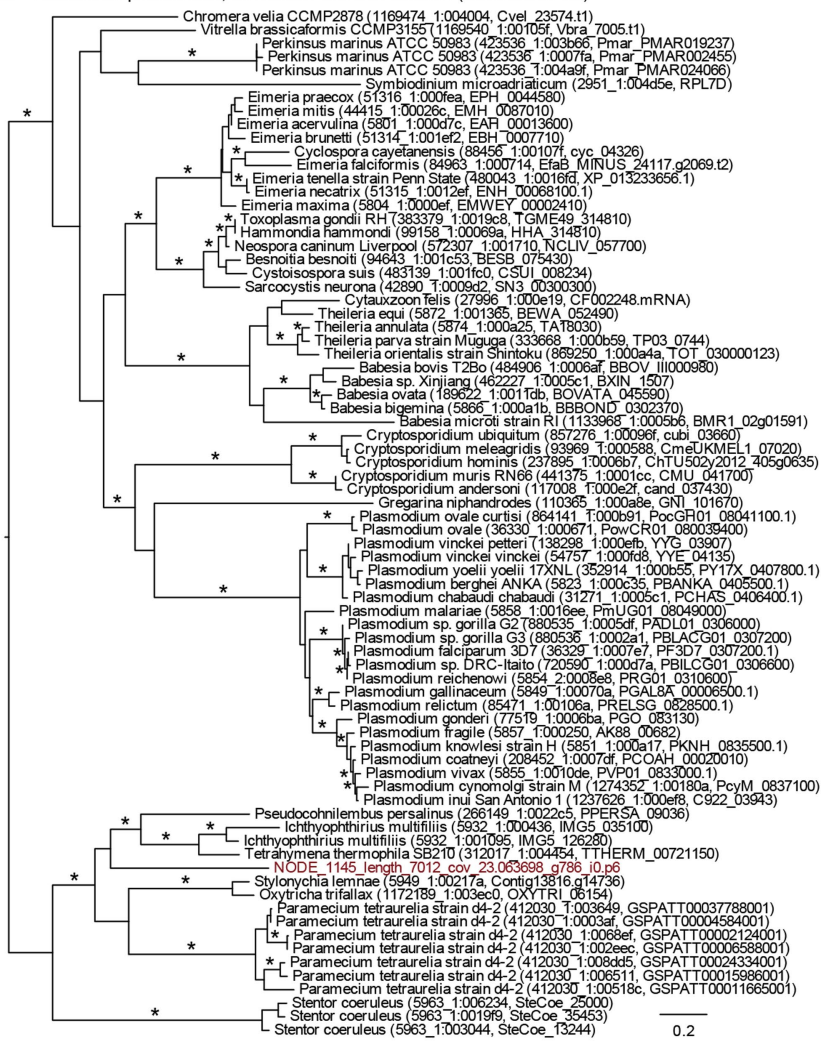

C Signal peptidase I (33467at33630) * Theileria orientalis strain Shintoku (869250_1:000928, TOT_030000073)

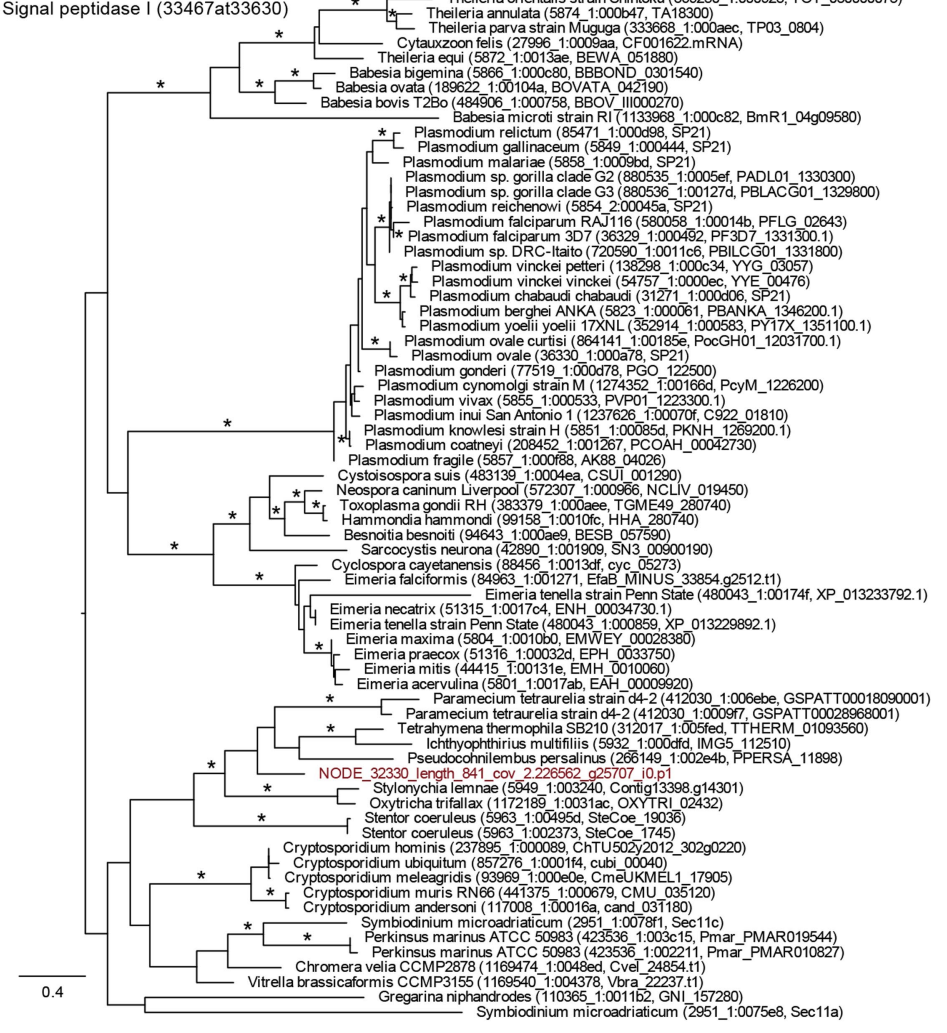

Extended Data Fig. 6 | Ciliate host phylogeny based on three different benchmarking universal single-copy orthologues. a-c, The orthologue group name and identifier is shown at the top of each phylogenetic tree (10862at33630 (a), 29724at33630 (b) and33467at33630 (c)). Comma-separated accessions in parentheses at tree leaves represent the 'int_prot_id' and 'pub_ gene_id' as provided by orthoDB. The corresponding open reading frame representing the ciliate host is highlighted in red. Asterisks highlight branches with a Shimodaira-Hasegawa-like approximate likelihood ratio test value $\geq 80 \%$ and an ultrafast bootstrap support $\geq 95 \%$. Phylogenies were rooted on the basis of the minimal ancestor deviation method. Scale bars indicate amino acid substitutions per site. 


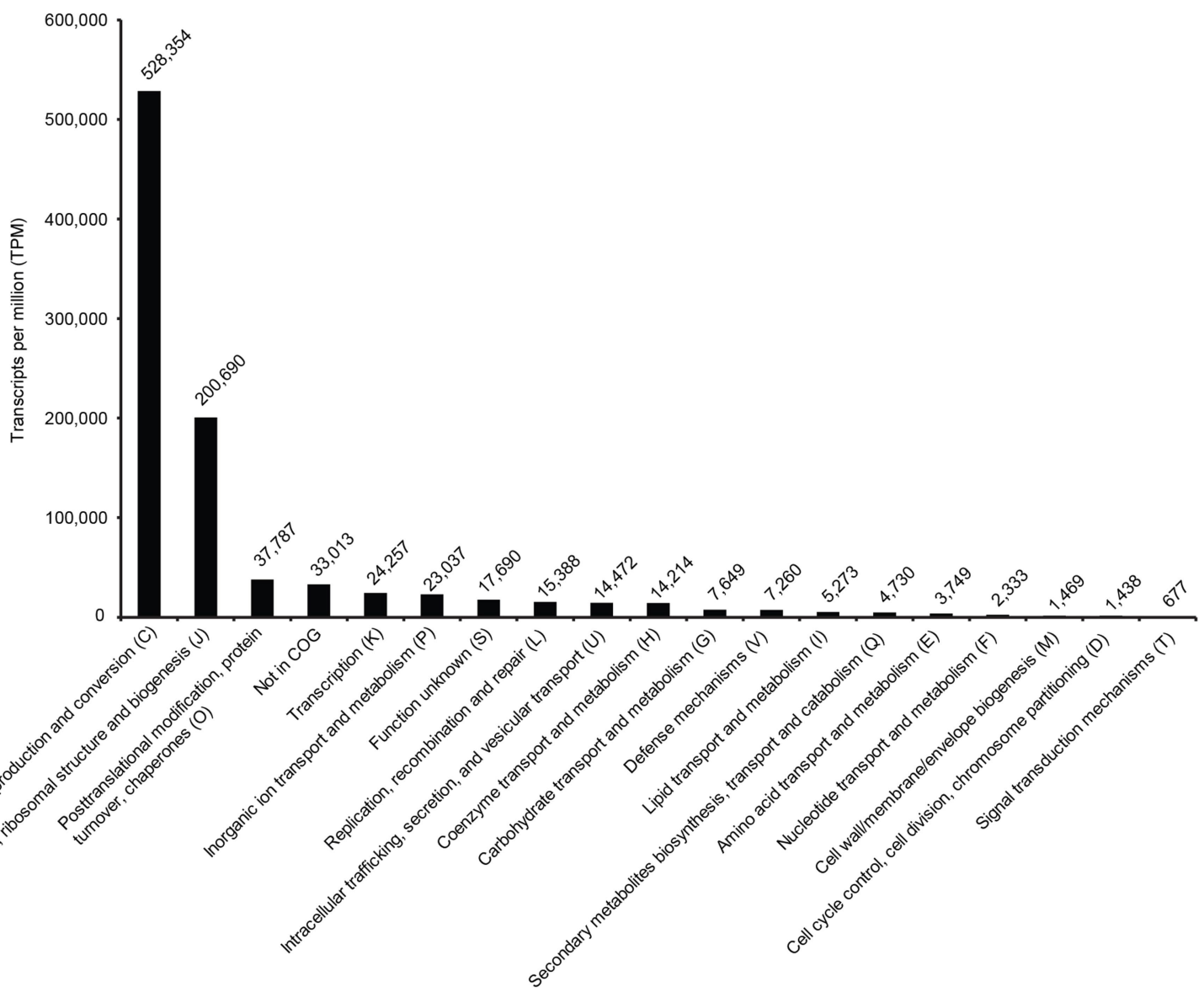

b

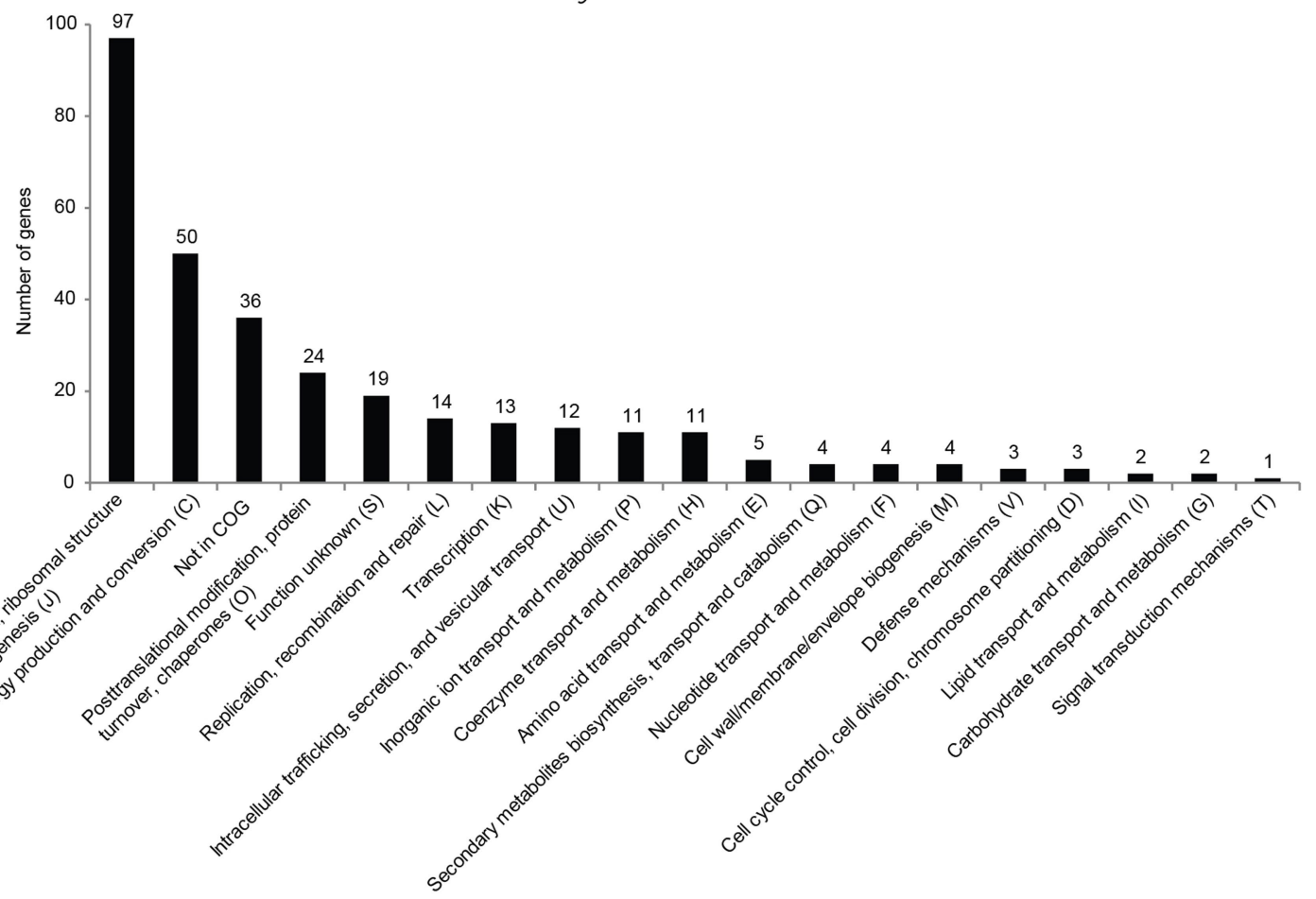

Extended Data Fig. 7 | Total gene transcription and number of genes per functional category. a, Bar chart showing the sum of TPM (indicated above each bar) of ' $\mathrm{Ca}$. A. ciliaticola' genes within different functional categories. For the TPM calculation, the Lake Zug bulk water metatranscriptome data (MT_18_C) were used. Genes with several assigned categories were not included in the analysis. b, Bar chart showing the number of genes encoded in the genome of ' $C a$. A. ciliaticola' assigned to different functional categories on the basis of clusters of orthologous genes analysis. The number of genes within each functional category is indicated above each bar. 


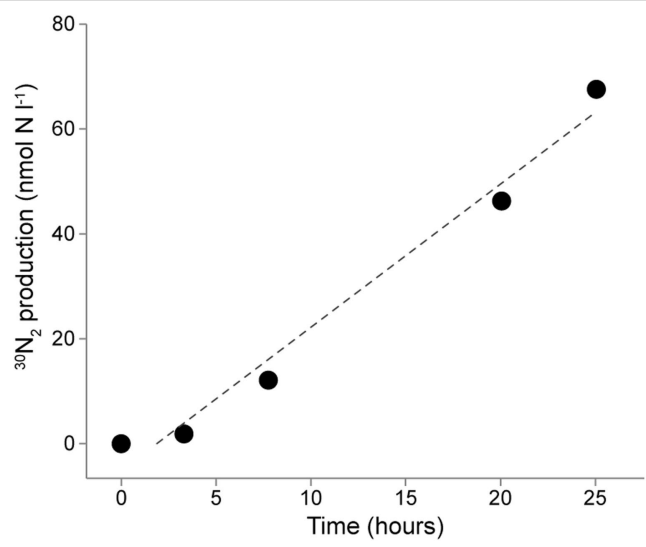

Extended Data Fig. 8 | Linear production of ${ }^{30} \mathrm{~N}_{2}$ from ${ }^{15} \mathrm{~N}$-labelled nitrate

and nitrite. Incubation of Lake Zug water containing ciliates (sampled in May 2019 from $189 \mathrm{~m}$ ) (Methods) amended with a mixture of ${ }^{15} \mathrm{~N}$-labelled nitrate and nitrite. The production of ${ }^{30} \mathrm{~N}_{2}$ was followed over the course of $25 \mathrm{~h}$. 
AtNTT1 (CAA89201)

AtNTT2 (CAA64329)

GSNTT1 (CAC80882)

StNTT1 (NP 001274794)

RPNTT1 (WP 004599717$)$

RPNTT3 (WP 004599498)

RPNTT4 (WP 004597746)

RPNTT5 (WP_004597024

PamNTT1 ( $(\overline{A A} E 46506)$

PamNTT2 (CAF22965)

PaANTT3 (CAF22964)

PamNTT4 (CAF23209)

PamNTT5 (CAT24067)

SNNTT1 (WP_013942850)

LaNTT1 (WP 012778542)

CCNTT (CAD29686)

AzoamicusNTT (ESZ 00147)

AtNTT1 (CAA89201)

ATNTT2 (CAA64329)

GSNTT1 (CAC80882)

STNTTI (NP_001274794)

RPNTT1 (WP_004599717)

RPNTT2 (WP 004599439)

RPNTT3 (WP 004599498)

RPNTT4 (WP 004597746)

PamNTT 1 (CA E 46506 )

PamNTT2 (CAF22965)

PamNTT 3 (CAF22964)

PamNTT4 (CAF23209)

PamNTT5 (CAT24067)

CtNTT1 (CAB39534)

SnNTT1 (WP_013942850)

LaNTTI (WP 012778542)

CCNTT (CAD2 29686)

HONTT (AAM80566)
AzOamicusNTT (ESZ_00147)

AtNTT1 (CAA89201)

AtNTT2 (CAA64329)

GSNTTI (CAC80882)
StNTTI (NP 001274794)

StNTT1 (NP_001274794)

RDNTT1 (WP (WP 004599439)

RPNTT3 (WP 004599498)

RPNTTT (WP 004599498 )

RPNTT4 (WP 004597746 )

PamNTT1 (CA E 46506)

PamNTT2 (CAF22965)

PamNTT3 (CAF22964)

PamNTT4 (CAF23209)

PamNTT5 (CAT24067)

CENTT1 (CAB39534)
SNNTT1 (WP 013942850$)$

SnNTT1 (WP 013942850)
LANTT1 (WP 012778542)

CCNTT (CADE 9686)

HONTT (AAM80566)

AONTT (AAM80amicusNTT (ESZ 00147)

AtNTT1 (CAA89201)

AtNTT2 (CAA64329)

GSNTT1 (CAC80882)

StNTT1 (NP 001274794)

RPNTT2 (WP 004599439 )

RPNTT3 (WP 004599498)

RPNTT4 (WP_004597746)

RPNTT5 (WP-004597024

PamNTT1 ( $\overline{\mathrm{AA}}$ E46506)

PamNTT2 (CAF22965)

PamNTT3 (CAF22964)

PamNTT4 (CAF23209)

PamNTT5 (CAT24067)

SnNTT1 (WP 013942850)

SnNTT1 (WP_013942850)
LaNTT1 (WP-012778542)

LCNTT (CAD2 9686)

HONTT (AAM80566)

AzoamicusNTT (ESZ 00147)

55 FKPLSOPCMGE

-RFPTKREAPSSYARRRRGCWRRSCLRRSDSAAVVASRKIFGVEVATLKKIIPLGLMFFCILFNYTILRDTKDVLVVTAKGSSAEIIPFIKTW

106 QTSLSLLATATVATLGQWFGKLVRSKAKDVDLLSPOFLQANGSAGSTDGSASVGADGIAKALPPKNELKKILPLGVMFFMILFNYTILRDTKDVLVVTT'--TGAEIIPFLKTY 216

58 VQGFDTKPQLF------_---G---QKKRCFPICKAFAAAAAGAA--DGQPLFVEKEOPKFMGELVTLKKIIPLGAMFECILFNYTILRDTKDVLVTAKGSSAEIIPFLKTW 156

23 -

21 -

32 -

24 - 69

(1) 69

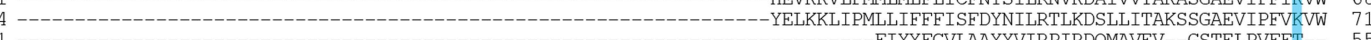

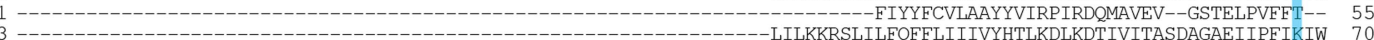

(1)

(1)

等

23 -

158 VNLPMAIGFMLLYTKLSNVLSKKALFYTVIVPFIIYFGGFGFVMYPLSNYIHPEA-LADKLLTTLGPRFMGPIAILRIWSFCLFYVMAELWGSVVVSVLFWGFANQITTVDEA 269 56 VNLPA TGMT IYTKT SNVISKKALFYTVIVPFTVYEGA

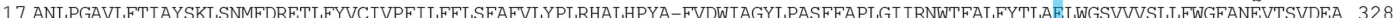
157 VNLPMAIGEMLLYTKLANVLSKEALFYTVILPFIAFFGAFGFVLYPLSNYFHPTA-FADKLLNTLGPRFLGPIAILRIWSFCLFYVMAELWGSVVVSVLFWGFANQITTVDEA 268 69 IVLPSAVIAMI IYVKLCDILKOENVFYVITSFFLGYFALFAFVLYPYPDLVHPDHKTIESLSLAYPN-FKWFIKIVGKWSFASFYTIAELWGTMMLSLLFWOFANOITKIAEA 180 75 GEMPMGVLFVILYSKLCNIMTTEOVFRIITSTFLFFFAIFGFILFPYKEFFHPNPELTNOYITVLPH-LKWFLIIWGOWSLVLFYIMGELWPVIVFTLLYWOLANKITKVEEA 186 67 LVLPSCVIFTILYVKLSNKLNFEYIFYSIVGTFLLFFLLFAYIIYPNQDIYHPNDAMINNLIASYPN-LKWFIKIGSKWSYALMYIFSELWSAVVINLMFWQFANHIFDTAKA 178 78 GVMPSAFLITVIYVKLVNRMKAENIFYLIISIFLTFFALFAYVIFPNHEMLHLRPVTVHNLTASLPN-LKWFILLLSKWSFSLFYIIAELWPNVVFALLFWQFVNNITTVEES 189 70 CVTPVAALFVIIYAKMINHLTFEKIFYYLSAFFISCFILFAFVIYPNIHIFHVHPDTLSDWMNKYPH-FKWYISLVGNWGYIVYYSLAELWPNIFYVLLFWQFTNELTTTEEA 181 68 GVVPAAILFMIIYAKLSNTLSRENLFYVTLLPFIIFFGLFAFVMYPAREVLMPHA-SAEALKAYLPGGWTGLAAAYENWMYSIFYILAELWGSVVLSLLFWGFANQITRVNEA 179 69 VLLPTAVLFTLIFTKLSNRESQEKVFYIVISTFLLFFGSFTYIFYPLRDVLHPHQ-LCDYLETILPAGEKGLIAMFRNWSFTLFYVICELWGSIVLTVLFWGFANEITKMTEA 180 72 AMFPGAILMTLLFTWLSNRLSREIVFYLITSLFLSYFFIFTFILYPIRDIIHPHA-TADYLETILPIGFKGLVAMFRYWTFTIFYVMSELWGSTVLFVLFWGFANQVTKISEA 183

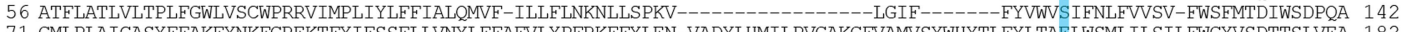
71 GMLPLAICASYFFAKFYNKFGREKTFYIFSSFLLVNYLFFAFVLYPFRKFFYLEN-VADYLHMILPVGAKGFVAMVSYWHYTLFYLTAELWSMLILSILFWGYVSDTTSLVEA 182 70 LVVPSAVVFMLIYAKLSNILNKQALFFAVLSPFVVFFALFPVVIYPCRHILHPTA-FADTLQSILPSGFMGFIAMLRNWTFAVFYVLSELWGSVMLSLMFWGFANEITKISEA 181
69 AVLPCAVIFMLIYAKLSNKLSKPQLFYTAVLPFLIFFALFATVLYPARDYLHPNA-LCDTLONTLPAGASGFIAIIRNWTYSIFYVMAELWGSVALSLLFWGFANDITKVSES 180 69 AVLPCAVIFMLIYAKLSNKLSKPQLFYTAVLPFLIFFALFATVLYPARDYLHPNA-LCDTLQNTLPAGASGFIAIIRNWTYSIFYVMAELWGSVALSLLLWGFANDITKVSES 180 69 VVLPSAVIMMVVYAKLCNIMSPQKVFYTIAWFFSLYLVFFAFVLYPYPEFFHPNHQTIEGLVIEYPN-LKWFIRICGQWSIASFYAISELYGSMMLSLLFWQFANQITKTSEA 180 70 LVTPCSIFAVIGYAKLSNLLSKQRLYFATLLPFAVYFLLFGFILYPMREYFNLSVDWIKECQSIYPL-LKDFFPAVAYWNYSLFYMMAELWGNMGIALLFWQFANQITPTTQA 181 69 CVTPAAVAFVVIYAKLCNVFNKETIFYIVVTPFLFFFAAFAFIIYPNFDVLHPSSTLINNLNNEYPA-FSGFINIYAYWSYSAFYVLAEIWGSAMVALMFWQFANEIVKISES 180 360 FLVSSPYIRDLATLVVAYGISINLVEVTWKSKLKAQFP-SP-------NEYSAFMGDFSTCTGVATFTMML-LSQYVFNKYGWGVARITPTVLLLTGVAFFSLI-------LF 457 358 FLVSSPYIRDLATLVVAYGISINLVEVTWKSKLKAQFP-SP-------NEYSAFMGDFSTCTGIATFTMML-LSQYVFKKYGWGVAAKITPTVLLLTGVAFFSLI-------LF 455 425 YLAKSAYIRNLALLVIAYGMSINIVEVSWKSKLKEAFP-DP---_-NSYSTFMGWFSTCTGSVTLIMML-LGRFIFRKFGWGFAALITPTVLGITGFLFFCLT------LF 522 (1)

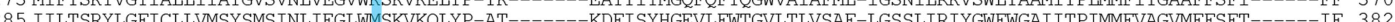

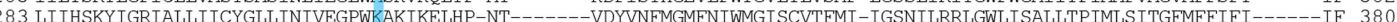
作 280 YIVKSKYLWLILICSAAFGFATNLVEAVWKAKTKELYP-TV-_ 278 TTSYILCLAILVIAYGISTNLVETTWKSLVKL 270 YI ANSKYLTCTAVLVISYNLVINLVEIVWKDQLROTYS-SA-_-_--LDYNRYMNNMTSAVGITATTTSL-FMSTMTTRFGTTRTALVTPTTMLVTSVGEFA M-284 YLLRSNYLLCIALIVISYNLVINLTEVLWKHOVRELYP-DP---_---NDYTLYMNHIVSIIGVVATLSSLFVSGNAIRKFGWTTTALITPIILAVTSLGFFSFF------FI 382 224 QIFSNPFIASMSLMMLINDAIGTIAYVLITDYSGTTFPNDV-------IAOTRFAANMDLFANI IOIFVQLILTRWLLVRYG---ASVV--FIVWTMTIVFFCLTM----TLV 320 270 DVLRTGPLLCIAVLVVGFGLTTNLIEVIWKENIRQLHP-TP-------QAYNAYINQLTSLIGTGAVCIAL-LSSWIFRKFTWTQIALTTPLCLLITSSAFFSSL-------LM 367 278 YLLRSPYMLLLALLVICYGICINLVEVTWKSQLKMQFP-NP-------NDYSAFMGNFSEWTGVVSVFVMLFIGGNVIRRFGWLTGALVTPIMVLVTGAVFFALV-------IF 376 278 YLTRSKYLGCIAILVLCYGIAINLIEVTWKSQLKIQFP-DP------NAYSTFMGRFSQITGVVTIFMMLFVGGNVIRRFGWGRAALVTPVVLLITGIAFFSFI------IF 376 268 MALNSKYLGYLVLLVICYGTAINLVEGPWKEKVRQLYP-TQ------NNSYAFMGQFIQWTGIVTIVFMI-LGSNILKSFRWFTSAIITPLMILITGGGFFVF------IF 365 275 MIFTSKYLGLLVTLILAYGISINLVEGVWKAKLRELYP-TK-------EAYTMFMGNFOAYQGVAAIIFML-VGSNILRRVSWATAAIFTPLMILVTGIGFFSFI------IF 372

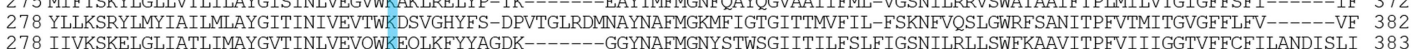
458 GGPFAPLVAKL-GMTPLLAAVYVGALQNIFSKSAKYSLFDPCKEMAYIPLDEDTKVKGKAAIDVVCNPLGKSGGGALIQQFM--ILSFGSLAN---STPYLGMILLVIVTAWLA 564 456 GGPFAPLVAKL-GMTPLLAAVYVGALQNIFSKSAKYSLFDPCKEMAYIPLDEDTKVKGKAAIDVVCNPLGKSGGALIOOFM--ILTFGSLAN---STPYLGVILLGIVTAWLAA 562 523 SRQLHPVVGML-GTTPLMLAVVLVGAAQNILSKSSKYSLFDPCKEMAYIPLDAEQKSKGKAAIDVIGNPMGKSGGSFIQQGL--IFAVGSLAA---STPYLAFILFVIVGMWIA 629 457 GAPLAPTLAKF-GMTPLLAAVYVGAMQNIFSKSAKYSLFDPCKEMAYIPLDEDTKVKGKAAIDVVCNPLGKSGGALIQQFM--ILTFGSLAS---STPYLGGVLLVIVLAWLG 563 371 DSVIAMNLTGILASSPLTLAVMIGMIQNVLSKGVKYSLFDATKNMAYIPLDKDLRVKGQAAVEVIGGRLGKSGGAIIQSTFFILFPVFGFIE---ATPYFASIFFIIVILWIF 480 383 EQHLGNIVNTLGYSSPLVIIVFIGGLWHVFAKSVKYSLFDATKEMVYIPLENEIKTKGKAAVDVMGAKIGKSIGAIIQFISFSIFPNAVHND---IAGLLMVTFIIVCILWLY 492 381 IEEIGTCFGDF--NLLYVAIIVGAIQNILSKSSKYSLFDSTKEMAYIPLSLELRTKGKAAVEVIGTKFGKSLGAFIQSLIFIIIPTATFDS---IIIYLLVIFIVMMNLWIW 487 385 EGFAGLIIANFILTDPALVAITIGAIQNVLSKSSKYTLFDSTKEMAYVPLEPEIKISGKAAADVIGTKLGKSGSAFLQSLIFIILPSASYQS---ISICLMIIFILTCVTWIW 494 378 DQQILSLFDGAILMSPLALAVSIGGIQNILAKGTKYSIWDTSREMLYIPLDDELKTKGKAAVDVISAKVGKSSSGLVQSIIFTLVPNATFTS---ISPILMVVFTFVCFAWIY 487 377 KDHLAGYIAAL-GTTPLFLAVIFGAAQNIMSKSAKYSLFDPTKEMAYIPLDDESKVKGKAAVDVVGARLGKSGGSIIQMG---LLAFGTLAT---ITPYIGAILMVIIAAWIV 482 368 RNDLADPVYILTGTTPLTIAVFFGAAQVCMSKACKYSVFDSTKEMAFIPLDYESKLLKGKAAIDGVGSRLGKSGGSLIHQSL--LMIFATVSS---SAPYVAVILIGVIIVWML 475

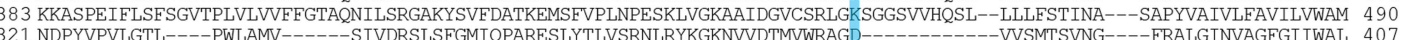
321 NDPYVPLGTL----PWLAMV------SIVDRSLSFGMIQPARESLYTLVSRNLRYKGKNVVDTMVWRAGD------------VVSMTSVNG----FRALGINVAGFGIIWAL 407

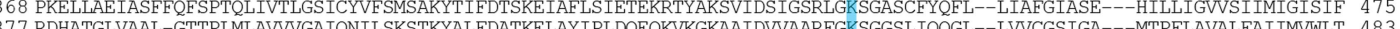
377 RDHATGLVAAL-GTTPLMLAVVVGAIQNILSKSTKYALFDATKELAY IPLDQEQKVKGKAAIDVVAARFGKSGGSLIQQGL--LVVCGSIGA---MTPFLAVALFAI IMVWLT 483 (1) 作

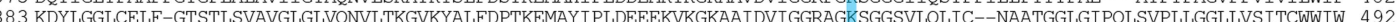
384 KNATYNLLSSL-GTTPVTAATFLGAAIVIISKVVKYSLFDPTKEMAYIPLDDELKTKGKAAVDVIGGRAGKAGGAFVQSTLLSIMATTNVLS---IAHIAFGVFFVVAILWII 492

Extended Data Fig. 9 | Multiple sequence alignment of 'Ca. A. ciliaticola' nucleotide transport protein with other bacterial and plastidic nucleotide transport proteins. Conserved residues that are important for transport efficiency, substrate specificity and counter exchange properties of ATP/ADP translocase from Arabidopsis thaliana ${ }^{86}$ are highlighted in blue, and numbered according to their position in Arabidopsis NTT1 (AtNTT1). All of these residues are conserved in the nucleotide transporter of ' $\mathrm{Ca}$. A. ciliaticola'. Accession codes are provided in parentheses, and further information regarding the aligned sequences is listed in Supplementary Table 8. 


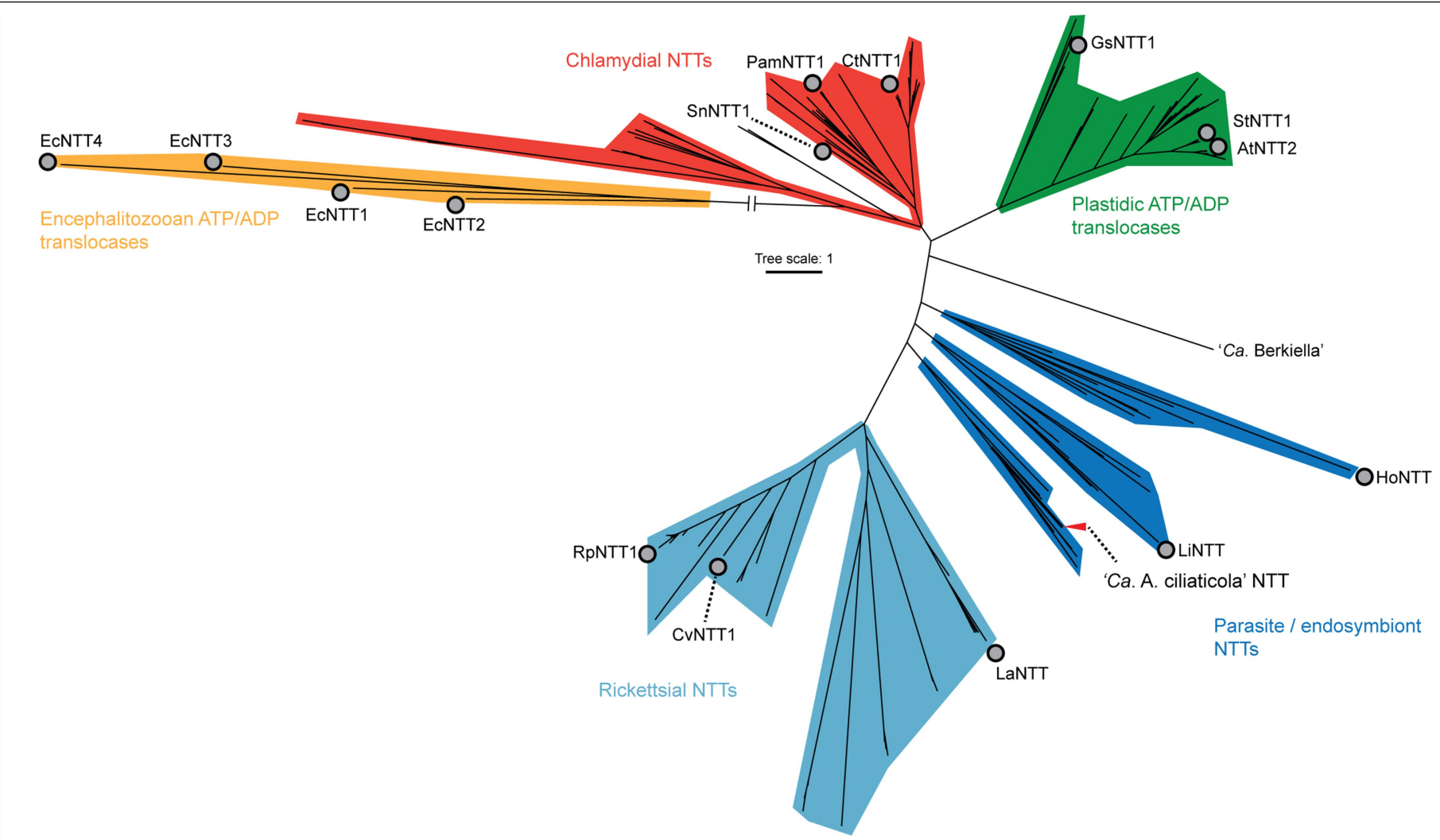

Extended Data Fig. 10 | Phylogenetic affiliation of ' $\mathrm{Ca}$. A. ciliaticola' ATP and ADP translocase and related nucleotide transporters. Maximumlikelihood phylogenetic tree based on amino acid sequences of bacterial and plastidic ATP/ADP translocases and related nucleotide transporters. ' $C a$. A. ciliaticola' ATP/ADP translocase (red arrow) clusters with environmental sequences related to the Holosporales and Caedibacter. The colours of groups reflect the predominant phylogenetic affiliation of taxa within a group. Sequences that have been shown to translocate ATP and ADP are marked with grey dots (Supplementary Table 7). Pam, Protochlamydia amoebophila; $\mathrm{Ct}$, Chlamydia trachomatis; $\mathrm{Sn}$, Simkania negevensis; Li, Lawsonia intracellularis; $\mathrm{Rp}$, Rickettsia prowazekii; La, Liberibacterasiaticus; Ec, Encephalitozoon cuniculi; $\mathrm{Cv}$, Caedimonas varicaedens; Ho, Holospora obtusa; $\mathrm{St}$, Solanum tuberosum; Gs, Galdieria sulphuraria; At, Arabidopsis thaliana. ATP/ADP translocases of $E$. cuniculi served as outgroup and are shown with truncated branch length, which is indicated as a break. 


\section{natureresearch}

Corresponding author(s): Jon Graf, Jana Milucka

Last updated by author(s): Jan 16, 2021

\section{Reporting Summary}

Nature Research wishes to improve the reproducibility of the work that we publish. This form provides structure for consistency and transparency in reporting. For further information on Nature Research policies, see Authors \& Referees and the Editorial Policy Checklist.

\section{Statistics}

For all statistical analyses, confirm that the following items are present in the figure legend, table legend, main text, or Methods section.

n/a Confirmed

$\bigotimes$ The exact sample size $(n)$ for each experimental group/condition, given as a discrete number and unit of measurement

$\square$ \A statement on whether measurements were taken from distinct samples or whether the same sample was measured repeatedly

The statistical test(s) used AND whether they are one- or two-sided

Only common tests should be described solely by name; describe more complex techniques in the Methods section.

Х $\square$ A description of all covariates tested

Х $\square$ A description of any assumptions or corrections, such as tests of normality and adjustment for multiple comparisons

$\triangle$ A full description of the statistical parameters including central tendency (e.g. means) or other basic estimates (e.g. regression coefficient)

AND variation (e.g. standard deviation) or associated estimates of uncertainty (e.g. confidence intervals)

W For null hypothesis testing, the test statistic (e.g. $F, t, r)$ with confidence intervals, effect sizes, degrees of freedom and $P$ value noted

Give $P$ values as exact values whenever suitable.

Х $\square$ For Bayesian analysis, information on the choice of priors and Markov chain Monte Carlo settings

Х $\square$ For hierarchical and complex designs, identification of the appropriate level for tests and full reporting of outcomes

Х $\square$ Estimates of effect sizes (e.g. Cohen's $d$, Pearson's $r$ ), indicating how they were calculated

Our web collection on statistics for biologists contains articles on many of the points above.

\section{Software and code}

Policy information about availability of computer code

Data collection Data collection and analysis was performed using following software as detailed in the manuscript and supplementary information. ionOS 4.0.4, Sequencher 5.4.6, SINA aligner 1.2.11, Arb 6.1, MathFISH webserver (07/2017), Daime 2.1, Trimmomatic 0.32/0.39, metaSPAdes 3.13.0/3.9.1, SPAdes 3.13.3/3.10.1, oriFinder 1.0, Prokka 1.13.3, Pseudo finder 0.11, CDD 3.18, TransAAP (04/2020), DNAplotter 18.1.0, eggNOG-mapper v1, MuscleWS 3.8.31, Jalview v2.11.1.0, SortMeRNA 2.1, Bowtie2 2.2.1.0, samtools 0.1.19, EDGE-pro 1.3.1, deepTools2 3.2.0, RNAmmer 1.5, RAxML 8.2.8, MAFFT online service v7, MAFFT 7.407, PhyloFlash 3.0/3.3b3, IQ-TREE 1.6.10/1.6.11, FigTree 1.4.4, iTOL 4, usearch 8.0.1623, MUSCLE 3.8.31, Bbmap 35.43, Matlab 2017b/2018b, Kaiju 1.7.3, rnaSPAdes 3.14.1, Transdecoder 5.5.0, BUSCO 4.0.6, MAFFT 7.407, FigTree 1.4.4, MAD 2.2, BLAST+ 2.9.0, MEGAN6 6.19.4, KEGG Automatic Annotation Server webserver (08/2020), HydDB webserver (08/2020), Zeiss ZEN 2.3, FEI xTM 6.2.6.3123

Data analysis

Data collection and analysis was performed using following software as detailed in the manuscript and supplementary information. ionOS 4.0.4, Sequencher 5.4.6, SINA aligner 1.2.11, Arb 6.1, MathFISH webserver (07/2017), Daime 2.1, Trimmomatic 0.32/0.39, metaSPAdes 3.13.0/3.9.1, SPAdes 3.13.3/3.10.1, oriFinder 1.0, Prokka 1.13.3, Pseudo finder 0.11, CDD 3.18, TransAAP (04/2020), DNAplotter 18.1.0, eggNOG-mapper v1, MuscleWS 3.8.31, Jalview v2.11.1.0, SortMeRNA 2.1, Bowtie2 2.2.1.0, samtools 0.1.19, EDGE-pro 1.3.1, deepTools2 3.2.0, RNAmmer 1.5, RAxML 8.2.8, MAFFT online service v7, MAFFT 7.407, PhyloFlash 3.0/3.3b3, IQ-TREE 1.6.10/1.6.11, FigTree 1.4.4, iTOL 4, usearch 8.0.1623, MUSCLE 3.8.31, Bbmap 35.43, Matlab 2017b/2018b, Kaiju 1.7.3, rnaSPAdes 3.14.1, Transdecoder 5.5.0, BUSCO 4.0.6, MAFFT 7.407, FigTree 1.4.4, MAD 2.2, BLAST+ 2.9.0, MEGAN6 6.19.4, KEGG Automatic Annotation Server webserver (08/2020), HydDB webserver (08/2020), Zeiss ZEN 2.3, FEI XTM 6.2.6.3123

For manuscripts utilizing custom algorithms or software that are central to the research but not yet described in published literature, software must be made available to editors/reviewers. We strongly encourage code deposition in a community repository (e.g. GitHub). See the Nature Research guidelines for submitting code \& software for further information. 
Policy information about availability of data

All manuscripts must include a data availability statement. This statement should provide the following information, where applicable:

- Accession codes, unique identifiers, or web links for publicly available datasets

- A list of figures that have associated raw data

- A description of any restrictions on data availability

The annotated genome of Ca. A. ciliaticola has been deposited at the European Nucleotide Archive (ENA) under the BioProject PRJEB27314 (accession number LR794158). Small subunit rRNA gene sequences of Ca. A. ciliaticola and the plagiopylean host have been deposited at ENA under BioProject PRJEB27314 and accession numbers LR798074-LR798089. Raw metagenomic and metatranscriptomic sequencing data of bulk water samples as well as single ciliate transcriptomes have been deposited at ENA under BioProject PRJEB36502 using the data brokerage service of the German Federation for Biological Data (GFBio). Metatranscriptomic sequencing data obtained in the year 2016 has been previously deposited at the Sequence Read Archive under BioProject PRJNA401219. Sequences used for phylogenetic trees are available under their respective accession codes at the SILVA rRNA database (http://www.arb-silva.de/; Fig. 2e, Extended Data Fig. 4), JGI Integrated Microbial Genomes and Microbiomes database (https://img.jgi.doe.gov/; Fig. 2e), EukRef-Ciliophora database (https://github.com/ eukref/curation; Fig. 2f), orthoDB (https://www.orthodb.org/; Extended Data Fig. 5) or NCBI protein database (https://www.ncbi.nlm.nih.gov/protein/; Extended Data Fig. 8 and 9). Genomes used for comparative analyses are available under their respective accession codes (see Methods) at NCBI (https:// www.ncbi.nlm.nih.gov/genome/; Fig. 2b, c). Transporter classification information (Supplementary Table 6) can be found at the Transporter Classification Database (https://www.tcdb.org/).

\section{Field-specific reporting}

Please select the one below that is the best fit for your research. If you are not sure, read the appropriate sections before making your selection. $\bigotimes$ Life sciences $\quad \square$ Behavioural \& social sciences $\quad \square$ Ecological, evolutionary \& environmental sciences

For a reference copy of the document with all sections, see nature.com/documents/nr-reporting-summary-flat.pdf

\section{Life sciences study design}

All studies must disclose on these points even when the disclosure is negative.

Sample size Sample size-based calculations were not relevant to this study and therefore no statistical methods were used to pre-determine sample size.

Data exclusions No data were excluded from analysis.

Replication Incubations experiments were performed in three independent biological replicates (bulk water samples) or two independent biological replicates (water enriched with ciliates, water without ciliates).

Metatranscriptomic analyses were performed separately using metatranscriptomic data obtained from two separate years (= independent biological replicates).

Genome reconstruction was independently performed twice using metagenomics data from separate two years (= independent biological replicates).

Please also refer to the Methods and Reproducibility section. All attempts at replication were successful. Similar results were obtained for all biological replicates.

Randomization Randomization was not relevant to this study as it was not a randomized controlled trial involving participant groups.

Blinding Blinding was not applicable because the study did not involve animals and/or human research participants. Furthermore, blinding was not possible because the person in charge of analyses was also responsible for taking the samples.

\section{Reporting for specific materials, systems and methods}

We require information from authors about some types of materials, experimental systems and methods used in many studies. Here, indicate whether each material, system or method listed is relevant to your study. If you are not sure if a list item applies to your research, read the appropriate section before selecting a response.

Materials \& experimental systems

$\mathrm{n} / \mathrm{a}$ Involved in the study

\ $\square$ Antibodies

Х $\square$ Eukaryotic cell lines

$\bigotimes \square$ Palaeontology

$\triangle \square$ Animals and other organisms

Х $\square$ Human research participants

\ $\square$ Clinical data

\begin{tabular}{|c|c|}
\hline $\mathrm{n} / \mathrm{a}$ & Involved in the study \\
\hline Х & $\square$ ChIP-seq \\
\hline 邓 & $\square$ Flow cytometry \\
\hline$\bigotimes$ & $\square$ MRI-based neuroimaging \\
\hline
\end{tabular}

